\title{
Gravity Anomalies, Isostasy, and Mantle Flow at the East Pacific Rise Crest
}

\author{
XUEJIN WANG AND JaMES R. COCHRAN
}

\author{
Lamont-Doherty Earth Obsenatory of Columbia University, Palisades, New York
}

\begin{abstract}
Bathymetry and gravity data obtained during a detailed Hydrosweep survey of the southern East Pacific Rise from $7^{\circ} \mathrm{S}$ to $9^{\circ} \mathrm{S}$ are used to investigate isostasy at the axis of a fast spreading mid-ocean ridge. In particular, we examine the manner in which the bathymetric crestal high is supported and how this support varies along the axis within the $160-\mathrm{km}$-long $7^{\circ} 12^{\prime} \mathrm{S}-8^{\circ} 38^{\prime} \mathrm{S}$ ridge segment. The crestal high stands about $400 \mathrm{~m}$ above the adjacent ridge flanks and has a nearly constant minimum axial depth for a distance of $140 \mathrm{~km}$. The summit is broad and flat, and an axial summit caldera is present for the entire length of the ridge segment. However, the width and cross-sectional shape of the crestal high vary systematically along the axis. It is broad with gentle slopes in the center of the segment but becomes progressively narrower and steeper toward the ends of the ridge segment. The ridge crest is marked by a free-air gravity anomaly high about $15-20 \mathrm{~km}$ wide with an amplitude of 10-15 mGal relative to the ridge flanks. Mantle Bouguer anomalies vary systematically along the axis with minimum values found near the center of the segment. The axial inantle Bouguer anomalies thus do not reflect the axial depth but are correlated with changes in the cross-sectional area of the crestal bathymetric high. The effects of cooling and subsidence away from the axis were removed from the bathymetry and free-air anomalies to isolate residual topographic and gravity anomalies associated with the ridge crest. The residual crestal bathymetric high was modeled as a flexural feature resulting from the upward buoyant load of a region of low density material centered beneath the axis. The lithosphere was treated as a broken plate, either with a constant flexural rigidity or an effective elastic thickness $T_{e}$ which grows at a rate proportional to the square root of distance from the axis. The best fitting values of $T$, for the constant rigidity case are in the range of $0.3-0.6 \mathrm{~km}$. For the growing plate model, $T$, increases at a rate of $0.2-0.3 \mathrm{~km}^{1 / 2}$. The gravity constrains the mass deficiency to extend to a depth of $20-30 \mathrm{~km}$ for both lithospheric models. We interpret this low-density material as a region of partial melt feeding magma to the ridge axis. The best fitting density anomalies imply that a 4-9\% melt fraction is present beneath the crestal high. Upwelling of melt to the axis is thus confined to a narrow zone within about $10 \mathrm{~km}$ of the axis. The mass deficiency and thus the upwelling partial melt are not distributed evenly along the ridge axjs but rather are concentrated in the central portion of the ridge segment. It thus appears that differences between the along-axis gravity and depth patterns observed at slow spreading and at fast spreading ridges are not the result of a change from threedimensional, focused upwelling at slow spreading ridges to two-dimensional sheetlike upwelling at fast-spreading ridges. Rather, the differences in axial gravity and depth between fast and slow spreading ridges reflect differences in the efficiency of the shallow along-axis magma distribution.
\end{abstract}

\section{INTRODUCTION}

The distinguishing morphologic characteristic of a fast spreading ( $>60 \mathrm{~mm} / \mathrm{yr}$ ) mid-ocean ridge axis, of which the East Pacific Rise (EPR) is the type example, is a crestal bathymetric high approximately $20 \mathrm{~km}$ wide and $200-400 \mathrm{~m}$ high [Menard, 1967; Macdonald, 1982]. The summit of the crestal high is often occupied by an axial summit caldera (ASC) [Macdonald and Fox, 1988] and is characterized by fresh lava flows, hydrothermal vents, and other indications of active or recent volcanism. The normal faults which bound abyssal hills and block out the tectonic fabric of the ridge flanks appear to form at distances of several kilometers from the axis [Lonsdale, 1977b; CYAMEX, 1981; Searle, 1984; Macdonald and Luyendyk, 1985]. Multichannel seismic reflection surveys have imaged a high-amplitude, relatively flat reflector at a depth of $1-2 \mathrm{~km}$ below the seafloor under the summit of the crestal high at portions of the East Pacific Rise axis [e.g., Herron et al., 1978, 1980; Hale et al., 1982; Detrick et al., 1987]. This reflector is underlain by a crustal low-velocity zone [Burnett et al., 1989; Harding et al., 1989; McClain et al., 1985; Toomey et al., 1990; Vera et al., 1990] and is generally interpreted to mark the top of a crustal magma chamber or melt lens [Sinton and Detrick, 1992].

\section{Copyright 1993 by the American Geophysical Union.}

Paper number 93JB01551.

0148-0227/93/93JB-01551\$05.00
Although the crestal bathymetric high resembles an elongated shield volcano [Lonsdale, 1977a] and is the locus of midocean ridge volcanism, the fact that it is a steady state feature which stands several hundred meters above the flanking abyssal hills precludes the crestal high from being of constructional volcanic origin. As pointed out by Madsen et al. [1984], this observation also implies that isostatic models treating the topographic relief as a load imposed on top of an elastic plate, which have been successfully applied to ridge flank morphology at fast spreading ridges [Cochran, 1979; $M c N u t t, 1979]$, are not appropriate for the crestal high.

The crestal bathymetric high is not reproduced by thermal models of lithospheric cooling which are able to predict heat flow and subsidence rates on the ridge flanks [e.g., Davis and Lister, 1974; Parker and Oldenburg, 1973; Parsons and Sclater, 1977]. Lewis [1981, 1982, 1983] was able to force a thermal subsidence curve to match the crestal high on profiles across the East Pacific Rise by varying the values chosen for the lithospheric thermal parameters, particularly the thermal diffusivity and the coefficient of thermal expansion. However, the values adopted in Lewis' model imply that old oceanic crust asymptotically approaches a maximum depth of less than $\mathbf{4 9 0 0}$ $m$, which is not in agreement with observations. The depths predicted for old oceans by Lewis' model could be brought more into line with observations by increasing the plate thickness to $90-100 \mathrm{~km}$ from his value of $60 \mathrm{~km}$. However, when this is done, heat flow in old oceanic regions is predicted to be only about $20 \mathrm{~mW} / \mathrm{m}^{2}$, which is significantly below what is observed [Louden, 1989; Stein and Stein, 1992]. When lithospheric thermal parameters which successfully predict observed oceanic depths and heat flow are used to fit ridge flank subsi- 
dence [e.g., Parsons and Sclater, 1977; Stein and Stein, 1992] and the results extrapolated to the ridge axis, they do not reproduce the crestal bathymetric high. Observed axial depths at fast spreading ridges are typically a few hundred meters shallower than predicted by fitting subsidence data from the adjacent ridge flanks [Cochran, 1986].

Madsen et al. [1984] modeled the crestal bathymetric high as the deflection resulting from a load imposed on the base of the lithosphere by buoyant upward forces. By jointly matching the bathymetry and gravity, they concluded that the compensation of the crestal high is centered at a depth of about 6-7 $\mathrm{km}$ below the seafloor and that the flexural rigidity is in the range of zero to about $1 \times 10^{19} \mathrm{~N} \mathrm{~m}$ (with a preferred value of $10^{18} \mathrm{~N} \mathrm{~m}$ ). When Madsen et al. [1984] allowed the flexural rigidity to vary with distance from the axis, they found that the upper bound on the rigidity increases from $10^{18} \mathrm{~N} \mathrm{~m}$ at the axis to about $10^{21} \mathrm{~N} \mathrm{~m}$ at distances of greater than $25 \mathrm{~km}$ from the axis. A flexural rigidity of $10^{21} \mathrm{~N} \mathrm{~m}$ is equivalent to an effective elastic plate thickness $T_{e}$ of $2.24 \mathrm{~km}$, similar to estimates obtained from ridge flank bathymetry [Cochran, 1979; McNutt, 1979]. The flexural rigidities of $10^{18}$ to $10^{19} \mathrm{~N}$ m estimated for the axial area are equivalent to a $T_{e}$ of $0.22-0.48 \mathrm{~km}$, reflecting the very thin, weak plate near the axis.

Kuo et al. [1986] extended Madsen et al.'s [1984] formula- tion to include the case where the lithosphere thickens away from the axis by adding unstressed material to the bottom of the plate. They analyzed the same set of stacked bathymetry and gravity profiles utilized by Madsen et al. [1984] and concluded that the data best fit their model when they assumed a very weak ridge axis $\left(T_{e}=0.1 \mathrm{~km}\right)$ and that $T_{e}$ increased away from the axis at a rate of $5.5 \mathrm{~km} / \mathrm{m} . \mathrm{y}^{1 / 2}\left(0.7 \mathrm{~km}^{1 / 2}\right)$.

In August and September 1991, we undertook a Hydrosweep multibeam sonar and gravity survey on the "superfast" spreading southern EPR. The surveyed area consists of the $150-\mathrm{km}$ offset Wilkes transform, located just south of $9^{\circ} \mathrm{S}$, and a 250 $\mathrm{km}$ length of the ridge axis and flanks extending north of the transform to about $7^{\circ} \mathrm{S}$. The spreading rate of this section of the EPR is about $144 \mathrm{~mm} / \mathrm{yr}$ [Demets et al., 1990]. Track lines were oriented nearly perpendicular to the ridge axis at a $5-\mathrm{km}$ spacing and complete bathymetric coverage was obtained to a distance of about $100 \mathrm{~km}(-1.5 \mathrm{Ma})$ from the axis on both flanks (Figure 1). The purpose of this study is to utilize the gravity and bathymetry data from this survey to investigate the origin and isostatic compensation of the crestal high. In particular, the systematic, closely spaced gravity lines and complete bathymetric coverage allow us to determine along-axis variations in the buoyant subcrustal mass responsible for the support of the crestal high and to deduce the pattern of mantle

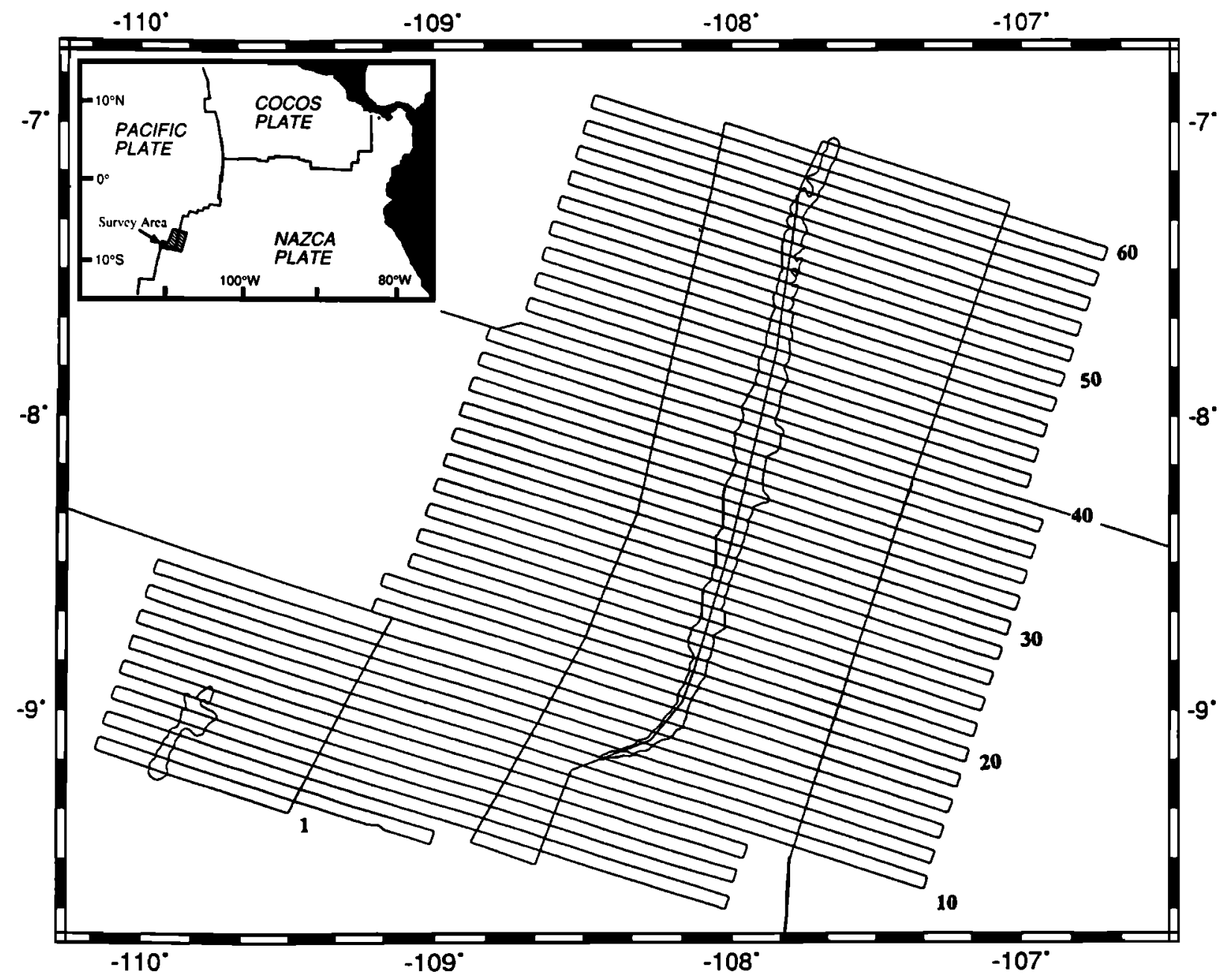

Fig. 1. Location map and track chart for the data from the southern East Pacific Rise used in this study. Numbers to the right of the survey are line numbers and correspond to the profile numbers in Figures 2 and 6 . Selected bathymetric contours are included to show the location of the ridge axis and Wilkes transform relative to the track lines. The ridge axis is outlined by the 3000-m contour to the north of the transform and by the $2900-\mathrm{m}$ contour to the south of the transform. Track lines are oriented nearly perpendicular to the ridge axis at $5-\mathrm{km}$ spacings. 
upwelling beneath a ridge segment of the southern EPR.

\section{MORPHOLOGY OF THE EAST PACIFIC RISE FROM $7^{\circ} \mathrm{S}$ TO $9^{\circ} \mathrm{S}$}

Bathymetric data were acquired during the 1991 survey using an Atlas Electronik Hydrosweep-DS formed-beam swath-mapping sonar system on the R/V Maurice Ewing [Chayes, 1991]. Hydrosweep is a 59-beam swath-mapping system with a beam width of $2.2^{\circ}$ per beam. The total width of the swath is $90^{\circ}$, so that an area roughly twice the mean water depth is mapped [Grant and Schreiber, 1990; Gutberlet and Schenke, 1989]. The data processing procedure developed for our data set is outlined by Cochran et al. [1993]. The bathymetric data were gridded at a 100-m grid interval, fit with a smooth surface and illuminated from the WNW to produce the image shown in Plate 1.
The southern portion of the survey area is dominated by the Wilkes transform and a region of highly disturbed seafloor extending for about $65 \mathrm{~km}$ north of the transform on the western (Pacific) ridge flank. This region, which we refer to as the Wikes nannoplate, has been affected by off-axis rifting resulting in the rotation of packets of seafloor [Goff et al., 1992, 1993]. Since we wish to investigate the isostatic mechanism at an undisturbed portion of the East Pacific Rise, we will concentrate this study on the northern portion of the survey area. Specifically, we will focus on a 160-km-long ridge segment extending from a small $(-1.2 \mathrm{~km}$ offset) overlapping spreading center (OSC) at $8^{\circ} 38^{\prime} \mathrm{S}$ to a larger $8-\mathrm{km}$ offset OSC at $7^{\circ} 12 ' \mathrm{~S}$. A series of fossil overlap basins are located on the ridge flank to the east of the $7^{\circ} 12^{\prime} \mathrm{S}$ OSC. They are oriented approximately along a flow line and extend to the eastern limit of the survey, indicating that the $7^{\circ} 12$ 'S OSC has been in existence for at

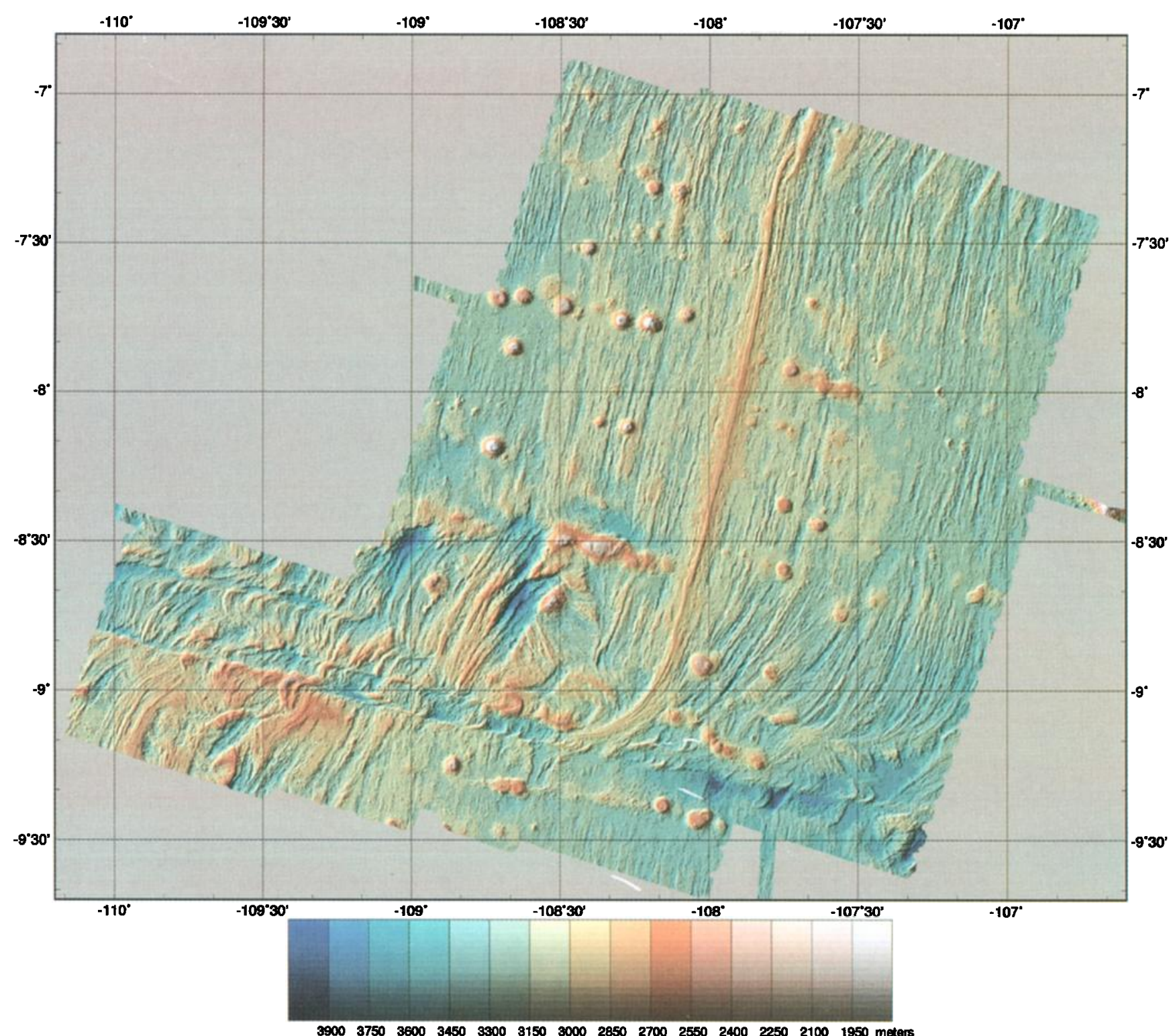

Plate 1. Bathymetric image of the southern EPR crest from $7^{\circ} \mathrm{S}$ to $9^{\circ} 40$ 'S produced from Hydrosweep swath-bathymetry data. Hydrosweep produces 59 water depth measurements athwartships over a swath with a width twice the water depth (i.e., swath is $\sim 6 \mathrm{~km}$ wide in this area). Line spacing was $5 \mathrm{~km}$, so total bathymetric coverage was obtained. To produce this image, the data were gridded on a 100-m grid with a weighting by beam number and fit with a smooth surface. The image has 16 color changes between $1800 \mathrm{~m}$ and $4200 \mathrm{~m}$ and is illuminated from the WNW. The location of the survey area is shown on Figure 1 . 

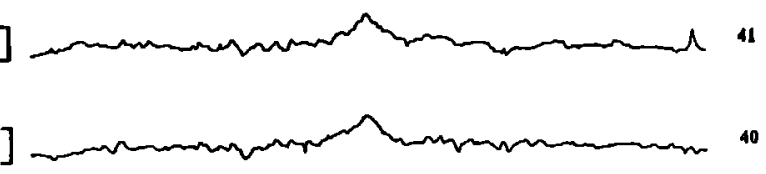

] ]

] מ

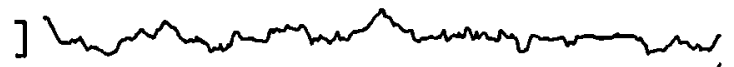

]

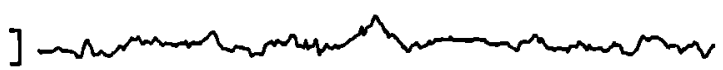

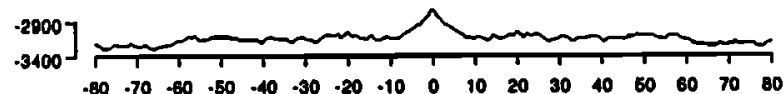

$7^{\bullet} 35^{\prime} S \cdot 7^{\bullet} 53^{\prime} S$
] ] 39

33

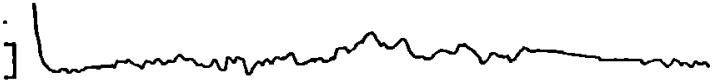

32

] 37

31

30

] 36

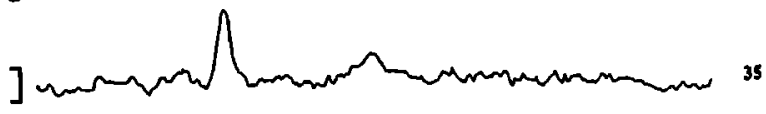

29

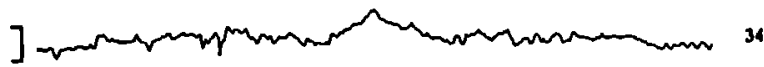

North of $7^{\circ} 35^{\prime} S$

]

]

] 46

] is

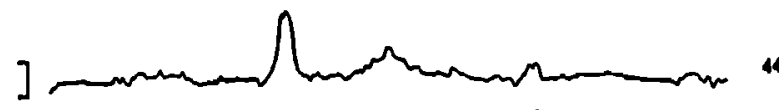

44

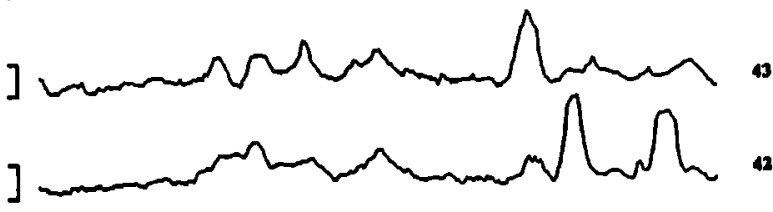

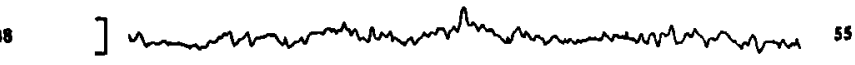

17

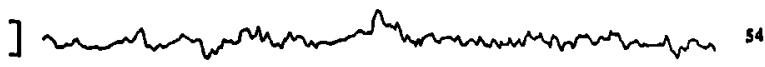

]

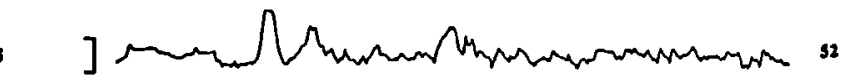

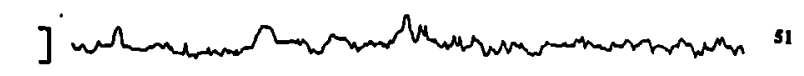

43

]

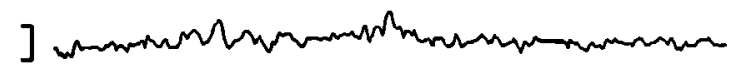
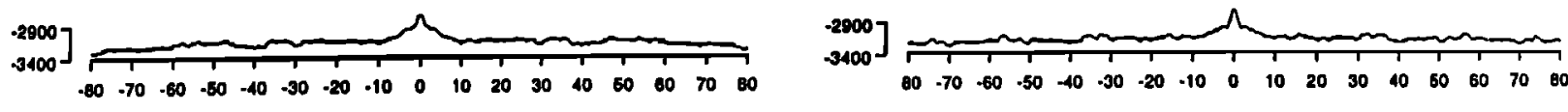

$\begin{array}{llllllllllllllllllllllllll}60 & -70 & .60 & -50 & -40 & -30 & -20 & -10 & 0 & 10 & 20 & 30 & 40 & 60 & 60 & 70 & 60\end{array}$

Distance from ridge ax/s $(\mathrm{km})$

Fig. 2. Bathymetry profiles from the $7^{\circ} 12^{\prime} \mathrm{S}-8^{\circ} 38^{\prime} \mathrm{S}$ segment of the East Pacific Rise. Profiles are constructed from Hydrosweep center beam data and are projected normal to the ridge axis. The bracket to the left of each profile spans depths of 2900 to $3400 \mathrm{~m}$; the number to the right of each profile identifies the line number as shown in Figure 1 . West is to the left on each profile. The ridge segment was divided into four sections on the basis of crestal morphology. The bottom, unlabeled profile for each set of profiles is a composite profile constructed by stacking and mirroring the profiles for that portion of the ridge axis. Seamounts were removed prior to stacking. Profiles 42 and 43 are highly disturbed and were not used in this study. 
least $\mathbf{1 . 5}$ m.y. and has remained in essentially the same location for that time. The small $8^{\circ} 38^{\prime} \mathrm{S}$ OSC is located immediately adjacent to a broad ridge which extends westward from the ridge axis and represents the northern boundary of the region of disturbed and disrupted seafloor. A distinct bend in the abyssal hill fabric occurs along a line extending away from the $8^{\circ} 38^{\prime} \mathrm{S}$ OSC for about $75 \mathrm{~km}$ onto the eastern flank (Plate 1). Eastern flank abyssal hills to the south converge toward the EPR axis, probably reflecting extensional rifting in the disturbed area on the western flank. Abyssal hills to the north parallel the present ridge axis, and no disruption of the abyssal hill fabric is apparent between the traces of the two OSCs. The $7^{\circ} 12$ 'S $8^{\circ} 38^{\prime} \mathrm{S}$ ridge segment thus appears to have been in existence as a stable tectonic element with relatively stationary boundaries for at least the past $1 \mathrm{~m} . \mathrm{y}$.

Bathymetric profiles across the ridge axis and extending to a distance of $80 \mathrm{~km}$ on each flank are shown in Figure 2 for each track line within the $7^{\circ} 12^{\prime} S-8^{\circ} 38^{\prime} S$ ridge segment. The profiles are constructed from center beam data and are thus spaced at $5-\mathrm{km}$ intervals. Location of the track lines is shown in Figure 1 . The ridge axis between $7^{\circ} 12$ 'S and $8^{\circ} 38^{\prime} \mathrm{S}$ consists of a $400-\mathrm{m}$-high, 10- to 20-km-wide crestal bathymetric high, roughly defined by the $3100-\mathrm{m}$ isobath. The crestal high is well defined because the ridge flanks are quite flat and do not subside significantly away from the axis. The average linear topographic gradient between 10 and $65 \mathrm{~km}$ from the axis is only $0.77 \mathrm{~m} / \mathrm{km}$, which is equivalent to $55 \mathrm{~m} / \mathrm{m}$.y.

The ridge crest morphology of the $7^{\circ} 12^{\prime} \mathrm{S}-8^{\circ} 38^{\prime} \mathrm{S}$ ridge segment was discussed by Cochran et al. [1993]. They found that the segment has a nearly constant minimum axial depth of about $2725 \mathrm{~m}$ for a distance of about $140 \mathrm{~km}$ from $7^{\circ} 22$ 'S to $8^{\circ} 35^{\prime} \mathrm{S}$ and that there is not a systematic pattern to the $20-30 \mathrm{~m}$ variations in axial depth along the segment (Figure 3). This observation contrasts with the pattern observed along the slower spreading (70-130 mm/yr) northern EPR, which has an undulating along-axis depth profile, with depths increasing systematically toward the ends of segments from a bathymetric sill [Macdonald and Fox, 1988].

Macdonald et al. [1988] have argued that the characteristic humped along-axis profile of the northern EPR is due to focused upwelling near the centers of ridge segments. They argued that magma must then migrate along the axis in the shallow level axial accretionary zone, resulting in a loss of hydraulic head with distance from the injection site, a graded depth profile and magma starved rift tips. Cochran et al. [1993] suggested that the nearly constant axial depths observed within ridge segments at the faster spreading southern EPR result from a broad, well-connected area of elevated temperatures beneath the axis, so that an efficient shallow subcrustal plumbing system extends the length of the ridge segment. As a result, the delivery of melt into the crustal magma chamber is relatively uniform along the segment, resulting in the uniform depth and appearance of the axial zone.

The summit of the crestal high is relatively broad $(1-2 \mathrm{~km}$ across) and flat, and an axial summit caldera (ASC), 500-1000 $\mathrm{m}$ wide and up to $50 \mathrm{~m}$ deep, is present for the entire length of the ridge segment (Figure 4) [Cochran et al., 1993]. At wellstudied areas of the northem EPR, the presence of an ASC and a broad, domal axial zone have been shown to be diagnostic of magmatically robust portions of the ridge axis [Haymon et al., 1991; Macdonald and Fox, 1988]. A magmatically vigorous region between $7^{\circ} 12 ' S$ and $8^{\circ} 38^{\prime} S$ is also indicated by the presence of numerous seamounts and lower oval topographic highs (Plate 1). The oval topographic highs almost always have a number of small cones, a few tens of meters high, on top of them, and appear to represent small off-axis volcanic features. The large, recently erupted lava field described by Macdonald et al. [1989] on the basis of SeaMARC II data is located within this ridge segment between $8^{\circ} 15^{\prime} \mathrm{S}$ and $8^{\circ} 20^{\prime} \mathrm{S}$. The flow appears to have originated from one or more small cones just east

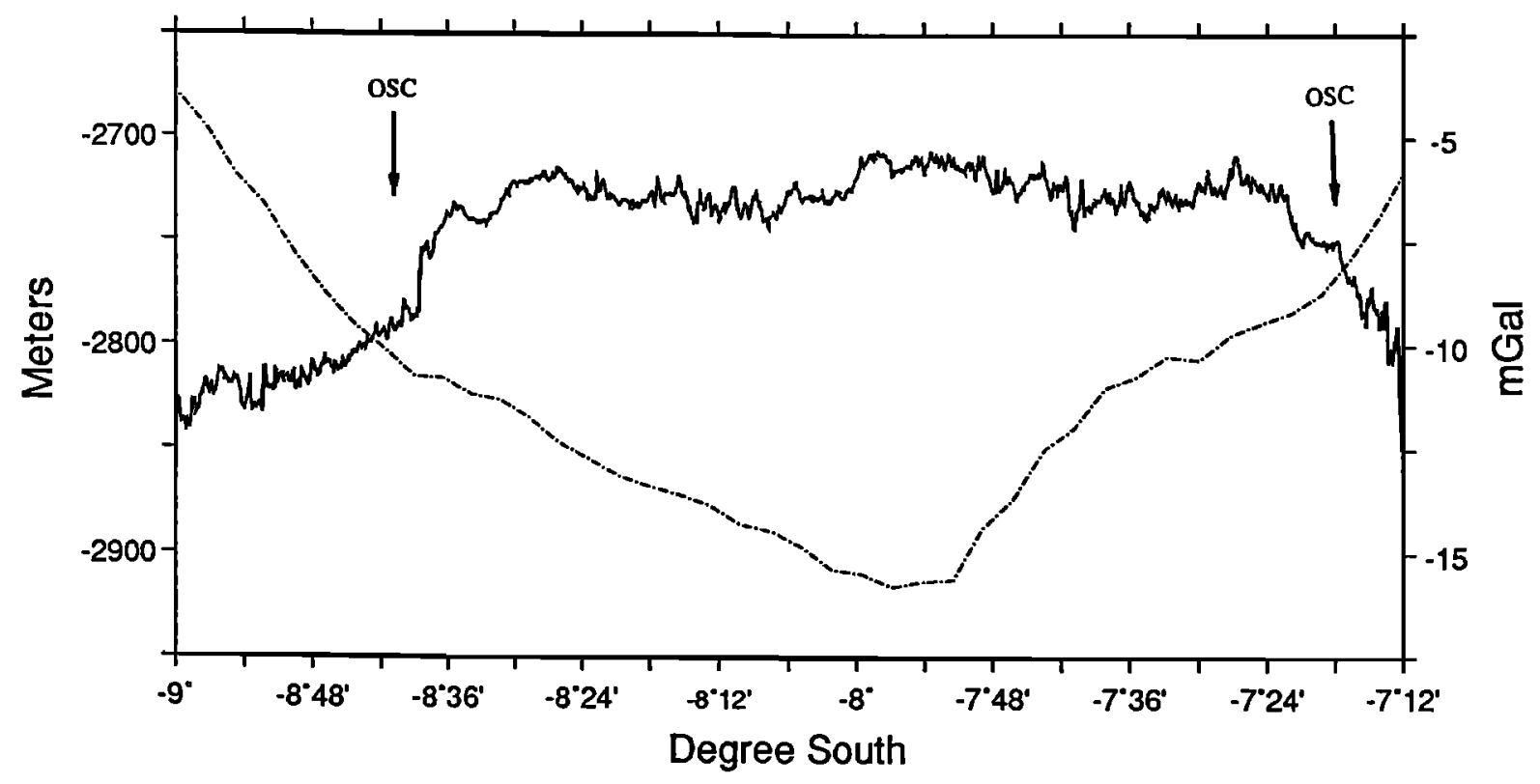

Fig. 3. Along-axis profiles of mantle Bouguer gravity anomalies and depth between $9^{\circ} \mathrm{S}$ and $7.2^{\circ} \mathrm{S}$ on the EPR. Solid line shows axial depth and dashed line mantle Bouguer anomalies. Axial depth profile was constructed from shallowest depth measurement on each ping of a line run along the axis. A 500-m running average was applied to the data. Mantle Bouguer anomaly profiles were constructed by connecting values calculated at the location of observed shipboard gravity measurements on each crossing of the axis. A five-point $(20 \mathrm{~km})$ running average was applied to the data. Only 2 of 40 observed data points differ by more than $1 \mathrm{mGal}$ from the smoothed curve shown here. Arrows mark the location of the small $8^{\circ} 49^{\prime} \mathrm{S}$ and $8^{\circ} 38$ 'S OSCs and the southern edge of the larger $7^{\circ} 12 ' \mathrm{~S}$ OSC. Note that the axial depth is constant for nearly the entire length of the $7^{\circ} 12^{\prime} \mathrm{S}-8^{\circ} 38^{\prime} \mathrm{S}$ ridge segment, while the gravity anomalies vary systematically along the axis. This pattern is unlike the highly correlated mantle Bouguer and bathymetry profiles at slow spreading ridges. 

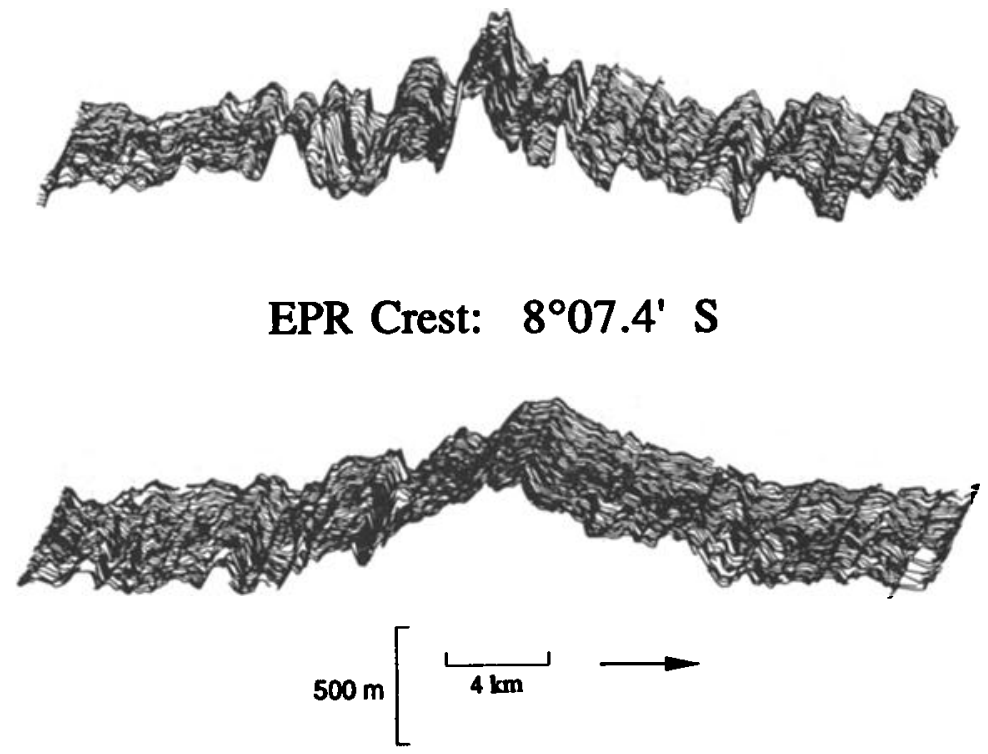

Fig. 4. Perspectives constructed from Hydrosweep swath bathymetry lines across the EPR axis (a) at $7^{\circ} 35.5^{\prime} \mathrm{S}$ and (b) at $8^{\circ} 07.4^{\prime} \mathrm{S}$. Both $s$ waths are viewed from the southeast and are plotted at a vertical exaggeration of 10 . Note the narrow, blocky crestal ridge and abyssal hills in Figure 4 a while Figure $4 \mathrm{~b}$ shows a broad gentle crestal high and smoother ridge flanks. In both swaths, the summit of the crestal high is broad and flat and an axial summit caldera (ASC) is present.

of the ridge axis and the oval topographic highs may have been built up by this type of flow.

Even though the axial zone, at the summit of the crestal high, has a very uniform depth and first-order appearance for nearly the entire length of the $7^{\circ} 12^{\prime} \mathrm{S}-8^{\circ} 38^{\prime} \mathrm{S}$ segment, Cochran et al. [1993] found that the shape of the crestal high varies significantly and systematically along strike. In the center of the segment, from $7^{\circ} 53^{\prime} \mathrm{S}$ to about $8^{\circ} 15^{\prime} \mathrm{S}$, the crestal high is broad with gentle slopes, and abyssal hills on its flanks are generally of low relief (Figures 2, 4, and 5). South of about $8^{\circ} 15 ' \mathrm{~S}$, the crestal high narrows progressively toward the OSC at $8^{\circ} 38^{\prime} S$ (Figures 2 and 5). The narrowing occurs mainly by steepening of the lower portion of the crestal high, while slopes on the upper crest remain relatively gentle.

The shape of the crestal high changes more dramatically to the north of a deval located at $7^{\circ} 53$ 'S. North of the deval, the upper portion of the crestal high becomes narrow and blocky (Figure 2), forming a steep-sided ridge roughly $200 \mathrm{~m}$ high (Figure 4). The average slope of the upper portion of the crestal high increases steadily from about $3^{\circ}$ to the south of $7^{\circ} 50^{\prime} \mathrm{S}$ to $25^{\circ}$ by $7^{\circ} 35^{\prime} \mathrm{S}$ (Figure 5). North of another deval at $7^{\circ} 35 \mathrm{~S}$, the lower portion of the crestal high becomes lower and less well developed, so that the axis is marked by a very steep, narrow, flat-topped ridge which is $300-400 \mathrm{~m}$ high and only 2 $5 \mathrm{~km}$ wide (Figure 2). The abyssal hills toward the northern end of the segment are quite well developed and are clearly bounded by normal faults (Figure 4).

Cochran et al. [1993] concluded that the variation in crestal morphology along the axis implies that deep mantle upwelling feeding magma to the shallow plumbing system beneath the East Pacific Rise does not occur evenly along the axis but rather is focused in discrete areas. Specifically, they suggested that upwelling beneath the $7^{\circ} 12^{\prime} \mathrm{S}-8^{\circ} 38^{\prime} \mathrm{S}$ segment occurs primarily beneath the central and, to a lesser extent, the southern portion of the segment. One of the primary objectives of this study is to use gravity and bathymetry data to quantitatively investigate this suggestion.

\section{GRAVITY DATA}

The gravity data presented here were collected using a Bodenseewerk KSS-30 marine gravimeter mounted on a gyrostabilized platform. The KSS-30 meter is an axially symmetric system utilizing a forced feed-back accelerometer and is therefore not subject to cross-coupling errors. A Bell BGM-3 gravimeter [Bell and Watts, 1986] was also mounted on R/V Maurice Ewing during the survey. However, it behaved erratically during the cruise and was subsequently removed for repairs. During periods of time when the Bell gravimeter was operating properly, data from the two meters were virtually identical.

The gravimeter output was logged at 6-s intervals. The raw data were filtered with a weighted average filter with a total filter width of $3 \mathrm{~min}$ in order to remove ship motions, and were sampled at 1-min intervals. The Eotvos correction and a theoretical gravity field were removed from the gravity values to determine the free-air anomalies. The ellipsoid used to calculate the theoretical gravity values is the 1980 Geodetic Reference System [Moritz, 1984]. Finally, a five-point median filter was applied to the free-air anomalies. Navigation during the survey was primarily by Global Positioning System (GPS) satellites. GPS navigation during the survey was always available for at least 21 hours and usually for more than 23 hours per day. Navigation during gaps in GPS coverage was constrained by the ship's Doppler log and transit satellite fixes. Periods of time without GPS navigation never exceeded 1 hour $\mathbf{4 0}$ min during the survey, and were more commonly in the range of 5-15 min.

The rms crossover error in the free-air gravity values, determined from 180 track crossings, is $1.7 \mathrm{mGal}$. The majority of the larger crossover errors are in regions of steep bathymetric and gravity gradients associated with the Wilkes transform and with the disturbed region to the north of the transform. The rms crossover error determined from 101 crossings in the portion of the survey considered in this study (lines 28-61 in 


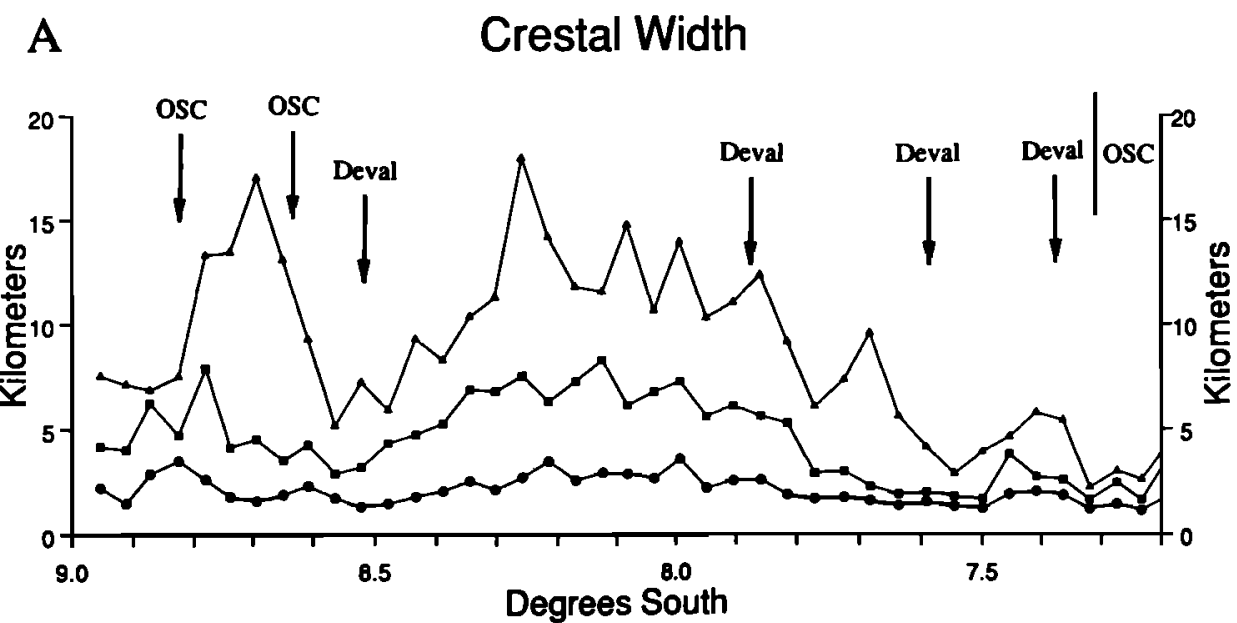

B Upper Crest Slope

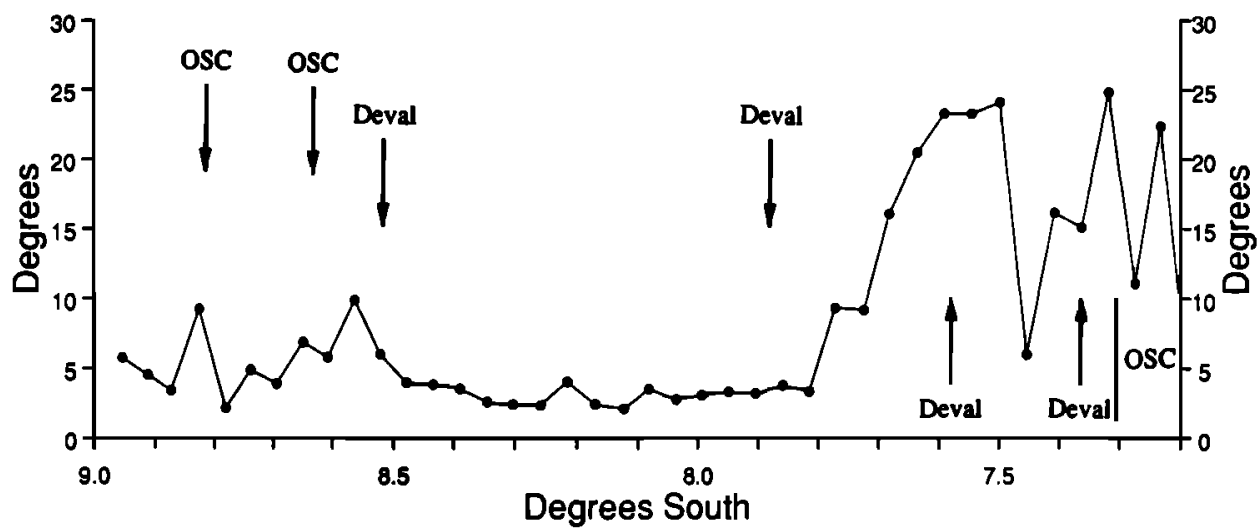

Fig. 5. (a) Along-axis variations in width of the crestal high along the southern EPR. The width of the region less than 100 $\mathrm{m}$ (circles), $200 \mathrm{~m}$ (squares), and $300 \mathrm{~m}$ (triangles) deeper than the minimum axial depth were determined for the center beam profile on each line across the axis. (b) Along-axis variations in the steepness of the upper portion of the crestal high. Plot shows the average slope in degrees of the area from $100 \mathrm{~m}$ to $200 \mathrm{~m}$ below the minimum axial depth determined from the center beam profile on each line across the axis.

Figure 1) is $1.5 \mathrm{mGal}$. Since the crossover errors are not distributed systematically along the individual track lines, application of corrections determined using the technique of Prince and Forsyth [1984] leads to only marginal improvement. We therefore chose to retain the observed free-air anomalies and not to adjust the data in this manner.

\section{Free-Air Gravity Anomalies}

A free-air gravity anomaly map with a contour interval of 5 $\mathrm{mGal}$ is shown in Plate 2 top. The map was constructed by gridding the gravity data on a 0.5 arc min $(\sim 0.9 \mathrm{~km})$ grid and fitting a smooth surface using a minimum curvature algorithm [Smith and Wessel, 1990]. The mean value of the gravity anomalies in the survey area $(17.0 \mathrm{mGal})$ was removed prior to contouring.

Large-amplitude gravity anomalies are associated with the Wilkes transform and the region of disturbed topography immediately to the north of it. The transform valley and its fossil extension to the east are associated with negative gravity anomalies of as much as $-20 \mathrm{mGal}$. These are flanked by positive gravity anomalies over the adjacent bathymetric highs with an amplitude of greater than $10 \mathrm{mGal}$. The two deep northsouth oriented rifts in the disturbed region are both character- ized by large negative free-air gravity anomalies. These anomalies are about $-25 \mathrm{mGal}$ for the western rift and $-30 \mathrm{mGal}$ for the eastern rift. The ridge extending west from the ridge axis near $8^{\circ} 40^{\prime} \mathrm{S}$, which marks the northern edge of the nannoplate, is characterized by a positive free-air anomaly of greater than $30 \mathrm{mGal}$. This large positive gravity anomaly as well as a bathymetric and gravity low immediately to the north (Plates 1 and 2 top) may reflect compressional deformation resulting from rotation of the nannoplate [Goff et al., 1993]. Circular free-air gravity highs are located over the off-axis seamounts throughout the region (Plate 2 top). These anomalies have amplitudes of up to $15-20 \mathrm{mGal}$ over the larger seamounts on the western flank.

The most prominent gravity feature of the northern portion of the survey area is a linear positive free-air anomaly over the ridge crest bathymetric high. Free-air gravity anomaly profiles across the ridge axis are shown in Figure 6 . The ridge crest free-air gravity anomaly in the $7^{\circ} 12^{\prime} \mathrm{S}-8^{\circ} 38^{\prime} \mathrm{S}$ ridge segment is about $15-25 \mathrm{~km}$ wide and has an amplitude of 10-15 mGal. The amplitude of the ridge crest gravity anomaly is about 3-5 mGal greater near the center of the segment than at the ends. The depth of the axis is nearly constant along the ridge segment, and the variation in the amplitude of the free-air anomaly thus reflects the variation in the width and shape of the ridge crest, 

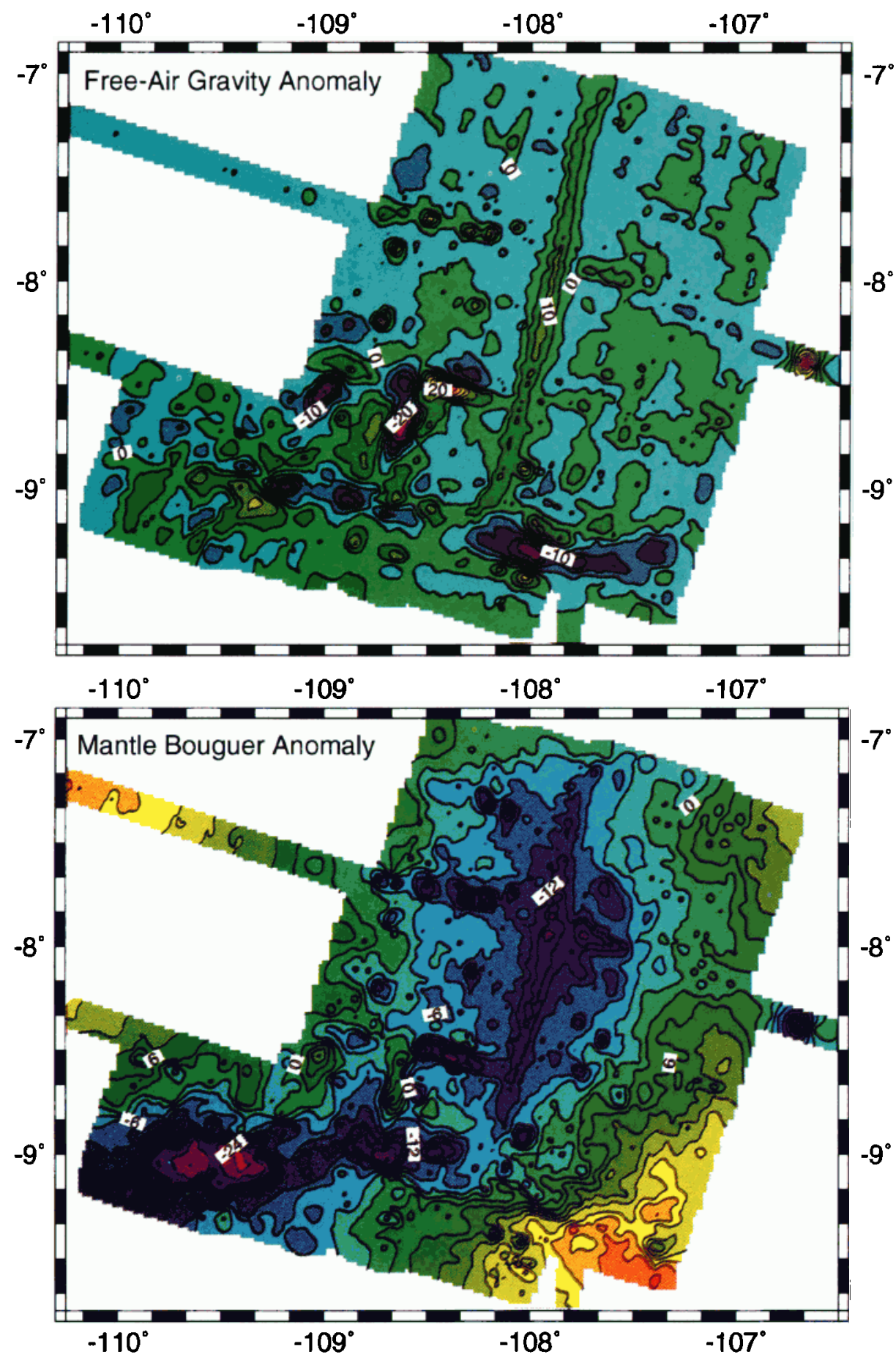

Plate 2. (top) Free-air gravity anomaly map of the $7^{\circ} \mathrm{S}-9^{\circ} \mathrm{S}$ survey area contoured at 5-mGal intervals. The observed free-air anomalies were interpolated onto a 0.5 arc $\min (-0.9 \mathrm{~km})$ grid and fit with a smooth surface using a minimum curvature algorithm [Smith and Wessel, 1990]. The mean value of the gravity anomalies in the survey area (17 mGal) was removed prior to contouring. (bottom) Mantle Bouguer anomaly map of the $7^{\circ} \mathrm{S}-9^{\circ} \mathrm{S}$ survey area contoured at 5 -mGal intervals. The calculated gravity effect of the water/crust and crust/mantle interfaces have been removed from the free-air anomalies assuming a constant crustal thickness of $6 \mathrm{~km}$. Densities of water, crust, and mantle are assumed to be 1030,2730 , and $3330 \mathrm{~kg} / \mathrm{m}^{3}$. 
South of $8^{\cdot} 15^{\prime} S$

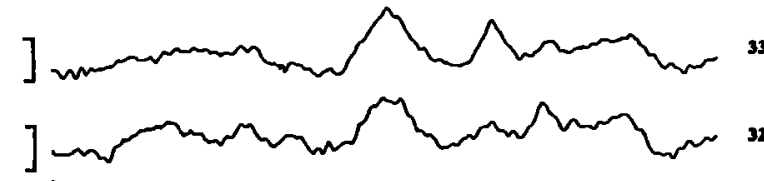

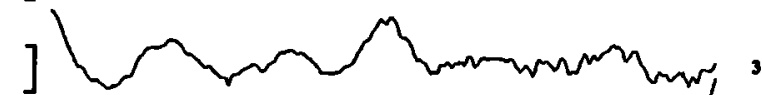
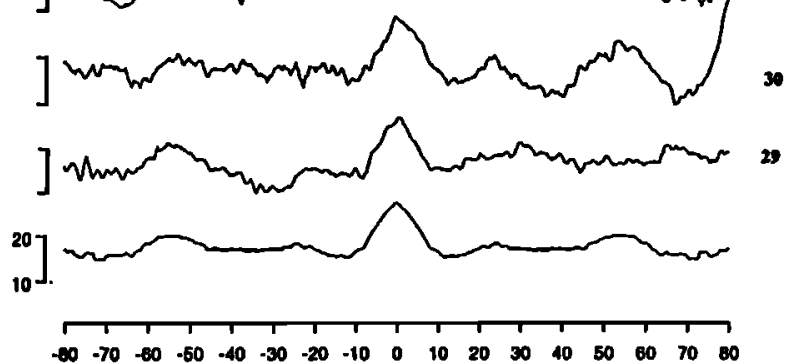

$7^{\circ} 35^{\prime} \mathrm{S}-7^{\circ} 53^{\prime} \mathrm{S}$
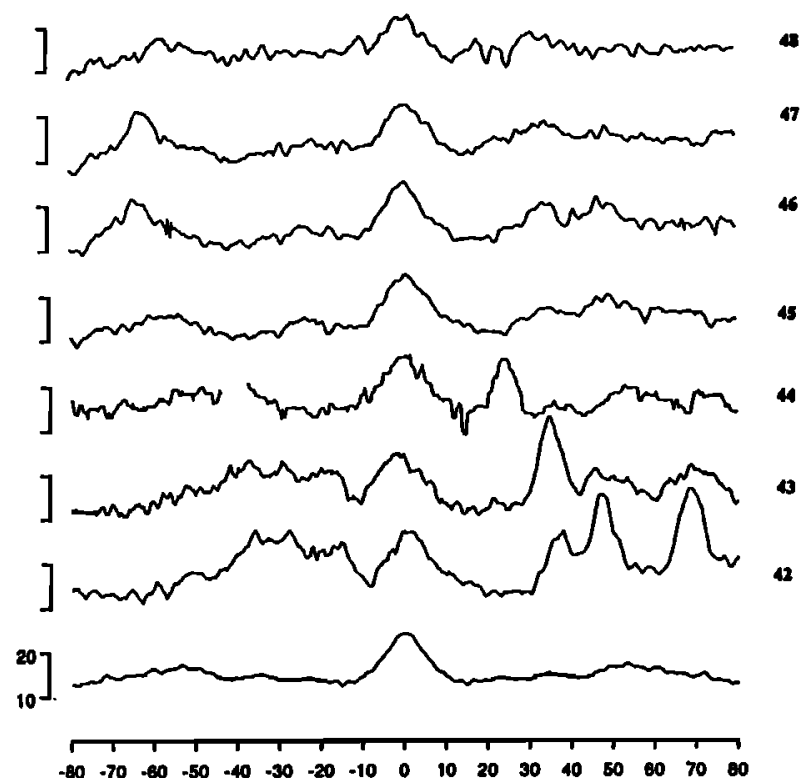

Distance from rldge axis $(\mathrm{km})$ $7^{\circ} 53^{\prime} \mathrm{S}-8^{\circ} 15^{\prime} \mathrm{S}$

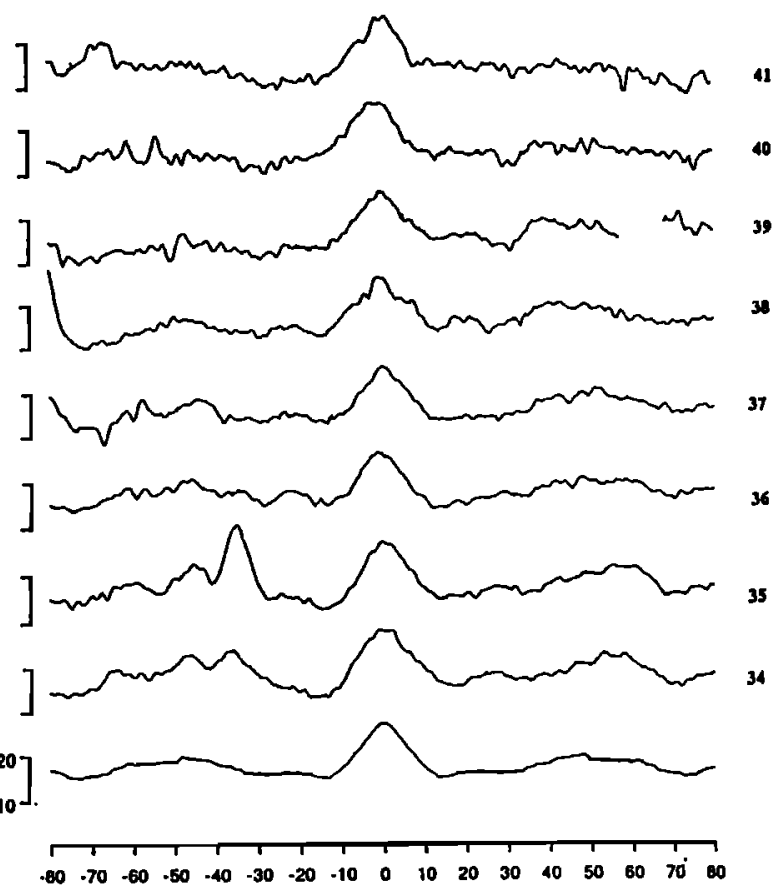

North of $7^{\circ} 35$ 's
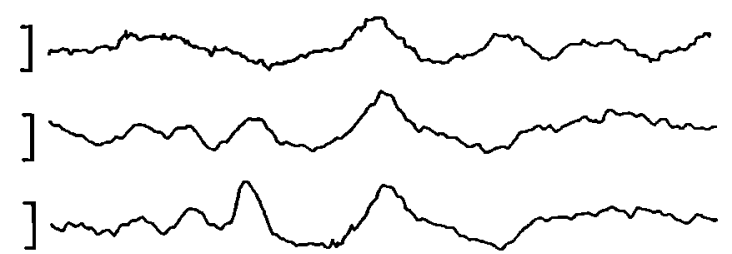

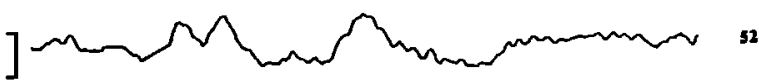

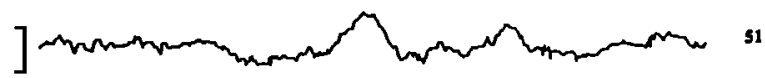

] ]
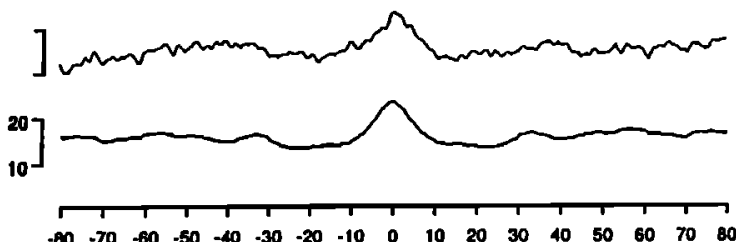

Fig. 6. Free-air gravity anomaly profiles from the $7^{\circ} 12^{\prime} \mathrm{S}-8^{\circ} 38^{\prime} \mathrm{S}$ segment of the East Pacific Rise. Profiles are projected normal to the ridge axis. The bracket to the left of each profile marks the range of $10-20 \mathrm{mGal}$; the number to the right of each profile identifies the line number as shown in Figure 1. West is to the left in all profiles. The ridge segment was divided into four sections on the basis of crestal morphology. The bottom, unlabeled, profile for each set of profiles is a composite profile constructed by stacking and mirroring the profiles for that portion of the ridge axis. Seamounts were removed prior to stacking. Profiles $\mathbf{4 2}$ and $\mathbf{4 3}$ are highly disturbed and were not used in this study. 
rather than variations in the axial depth.

\section{Mantle Bouguer Gravity Anomalies}

A mantle Bouguer gravity anomaly map of the $7^{\circ} \mathrm{S}-9^{\circ} 40^{\prime} \mathrm{S}$ area is also shown in Plate 2 bottom. We calculated the gravity effect of the water/crust and crust/mantle interfaces using the method of Parker [1973], assuming the densities of the water, crust, and mantle to be 1030,2730 , and $3300 \mathrm{~kg} / \mathrm{m}^{3}$, respectively. A constant crustal thickness of $6 \mathrm{~km}$ was assumed. The topography data were regridded at a 0.5 arc $\min (\sim 0.9 \mathrm{~km})$ interval for the calculation, and a cosine taper was applied to the outer $5 \%$ of the data to minimize edge effects. Four terms were retained in the series expansion of the gravity effect of the topography and Moho. The calculated gravity grid was resampled at the location of observed gravity values and the gravity effect of the topography and Moho relief was subtracted from the free-air anomalies. The track line mantle Bouguer gravity values were then regridded at a 0.5 arc min interval to produce the map shown in Plate 2 bottom.

The primary density contrast affecting the mantle Bouguer anomalies is that between mantle and water, and the anomalies are not sensitive to the exact distribution of density with depth in the crust. As pointed out by Prince and Forsyth [1988, p 8057], "as long as a constant crustal thickness is assumed, the gravitational attraction for this simple model with uniform crustal density is almost identical (less than $1 \mathrm{mGal}$ difference) to a more realistic model with densities increasing from 2.2 or $2.3 \mathrm{Mg} / \mathrm{m}^{3}$ in the uppermost crust to 2.9 to $3.0 \mathrm{Mg} / \mathrm{m}^{3}$ in layer 3."

The main features of the mantle Bouguer anomaly map (Plate 2 bottom) are elongated gravity lows over the Wilkes transform and the ridge crest to the north. The minimum value of the axial mantle Bouguer anomaly $(-16 \mathrm{mGal})$ is located just north of $8^{\circ} \mathrm{S}$, in the center of the segment. Values increase toward the ends of the segment, reaching $-6 \mathrm{mGal}$ at the $7^{\circ} 12 \mathrm{~S} \mathrm{OSC}$ and $-10 \mathrm{mGal}$ at the $\mathbf{8}^{\circ} 38^{\prime} \mathrm{S}$ OSC (Figure 3). Axial mantle Bouguer anomalies continue to increase smoothly to the south of the $8^{\circ} 38^{\prime} \mathrm{S}$ OSC reaching $-4 \mathrm{mGal}$ at $9^{\circ} \mathrm{S}$. Mantle Bouguer anomalies also increase steadily away from the axis. This increase in the mantle Bouguer anomaly with age is expected and reflects the increase in mantle density by cooling and thickening of the lithospheric plate with age. However, the gravity contours do not parallel the ridge axis. The mantle Bouguer anomaly low is broadest over the center of the $7^{\circ} 12^{\prime} \mathrm{S}-8^{\circ} 38^{\prime} \mathrm{S}$ segment and narrows toward both ends. This reflects the presence of a subsurface mass deficiency beneath the center of the ridge segment.

Gravity studies of mid-ocean ridge crests at a range of spreading rates have shown a systematic relationship between along-axis variations in the mantle Bouguer anomaly, the axial depth profile, and spreading rate [Phipps Morgan, 1991; Lin and Phipps Morgan, 1992]. Slow spreading ridges typically show large variations in both along-axis depth and axial mantle Bouguer anomaly [Kuo and Forsyth, 1988; Lin et al., 1990; Blackman and Forsyth, 1991]. In contrast, fast spreading ridges show more subdued along-axis topography and mantle Bouguer anomaly variations [Madsen et al., 1990]. The spreading rate dependent changes in the character of the along-axis gravity and bathymetry variations have been ascribed to a fundamental change from a basically two-dimensional mantle flow pattern under fast spreading ridges to a more three-dimensional pattern of focused upwelling beneath slow spreading ridges [Parmentier and Phipps Morgan, 1990; Lin and Phipps Morgan, 1992].

Unlike observations at more slowly spreading ridges, the along-axis depth and gravity profiles for the southern EPR are not similar (Figure 3). The axial depth is constant for nearly the entire length of the $160-\mathrm{km}$-long $7^{\circ} 12^{\prime} \mathrm{S}-8^{\circ} 38^{\prime} \mathrm{S}$ ridge seg- ment, continuing the observed trend of more subdued axial ridge variations with increasing spreading rate. However, in spite of the constant axial depth, the gravity anomalies vary systematically along the ridge. Both the amplitude of the variation in mantle Bouguer anomaly $(10 \mathrm{mGal})$ and the gradients $(>0.1 \mathrm{mGal} / \mathrm{km}$ ) are similar to those observed at the northern EPR [Madsen et al., 1990; Lin and Phipps Morgan, 1992].

Minimum mantle Bouguer anomalies are located at $8^{\circ} \mathrm{S}$, near the center of the ridge segment. The crestal bathymetric high is widest at this location and the mantle Bouguer anomalies reflect the variation in the width of the crestal high (Figures 3 and 5). Scheirer and Macdonald [1993] also found that axial mantle Bouguer anomalies for portions of the northern EPR are correlated with axial cross-sectional area, although there the anomalies appear correlated with axial depth as well.

The gravity data imply the presence of a subsurface mass deficiency concentrated at the center of the ridge segment. This suggests that deep mantle upwelling at the southern East Pacific Rise is not two-dimensional. Specifically, upwelling does not occur evenly along the axis but rather is preferentially focused in discrete regions. We will investigate this hypothesis by quantitatively modeling the gravity and bathymetry of the ridge crest within the $7^{\circ} 12 ' S-8^{\circ} 38^{\prime} S$ ridge segment.

\section{ANALYSIS OF GRAVITY AND BATHYMETRY DATA}

We wish to examine the variation in gravity and bathymetry along the ridge crest within the $7^{\circ} 12^{\prime} \mathrm{S}-8^{\circ} 38^{\prime} \mathrm{S}$ ridge segment. Cochran et al. [1993] divided the ridge segment into four sections on the basis of variations in axial morphology (Figs. 2 and 5). Stacked, mirrored crestal bathymetry and gravity profiles for the four sections are compared in Figure 7. The individual center beam profiles and the stacked, mirrored bathymetric profile from each of the four sections are shown in Figure 2. Free-air gravity anomaly profiles for each line and stacked, mirrored gravity anomaly profiles from the same four sections of the EPR are shown in Figure 6. Data collected over seamounts were eliminated from both gravity and bathymetry profiles prior to stacking. The divisions at $7^{\circ} 35^{\prime} \mathrm{S}$ and $7^{\circ} 53^{\prime} \mathrm{S}$ are at the locations of devals which also mark a change in the cross-sectional shape of the ridge crest (Figs. 2 and 5). The division at $8^{\circ} 15^{\prime} \mathrm{S}$ marks the location at which the ridge crest begins to narrow toward the $8^{\circ} 38^{\prime} \mathrm{S}$ OSC (Figure 5).

Although very significant changes in crestal morphology occur along the $7^{\circ} 12^{\prime} \mathrm{S}-8^{\circ} 38^{\prime} \mathrm{S}$ ridge segment (Figures 2 and 7 ), along-axis changes in the free-air anomalies are less profound (Plate 2 top and Figure 6). The crestal free-air gravity anomaly in center of the ridge segment $\left(7^{\circ} 53 \mathrm{~S}-8^{\circ} 15\right.$ 'S) is slightly wider than in the other three sections. However, the primary manifestation in the free-air gravity anomalies of the along-axis morphologic variation is an increase in the amplitude of the ridge crest anomaly relative to values on the ridge flanks from about $9.5 \mathrm{mGal}$ at the northern end of the segment to about $12.5 \mathrm{mGal}$ in the center. The gravity anomaly then decreases in amplitude by about $1 \mathrm{mGal}$ from the center to the southern portion of the ridge segment.

A component of the bathymetric and gravity expression of the ridge crest is due to cooling and thermal contraction of the lithosphere away from the ridge axis. In order to isolate the anomalous gravity and bathymetry of the crestal high, the effects of thermal subsidence need to be removed from the observed profiles. Calculations are simplified by the fact that the section of ridge crest which we are considering is well away from any significant offset of the axis and has a simple twodimensional geometry.

Subsidence rates away from the ridge axis in this area are very low. The best fitting square root of age subsidence rate $\left(C_{1}\right.$ of Parsons and Sclater [1977]) for distances of 10-64 km from the axis is only $70 \pm 8 \mathrm{~m} / \mathrm{m} . y .{ }^{1 / 2}$. There is a distinct bathymet- 
(a) Gravity

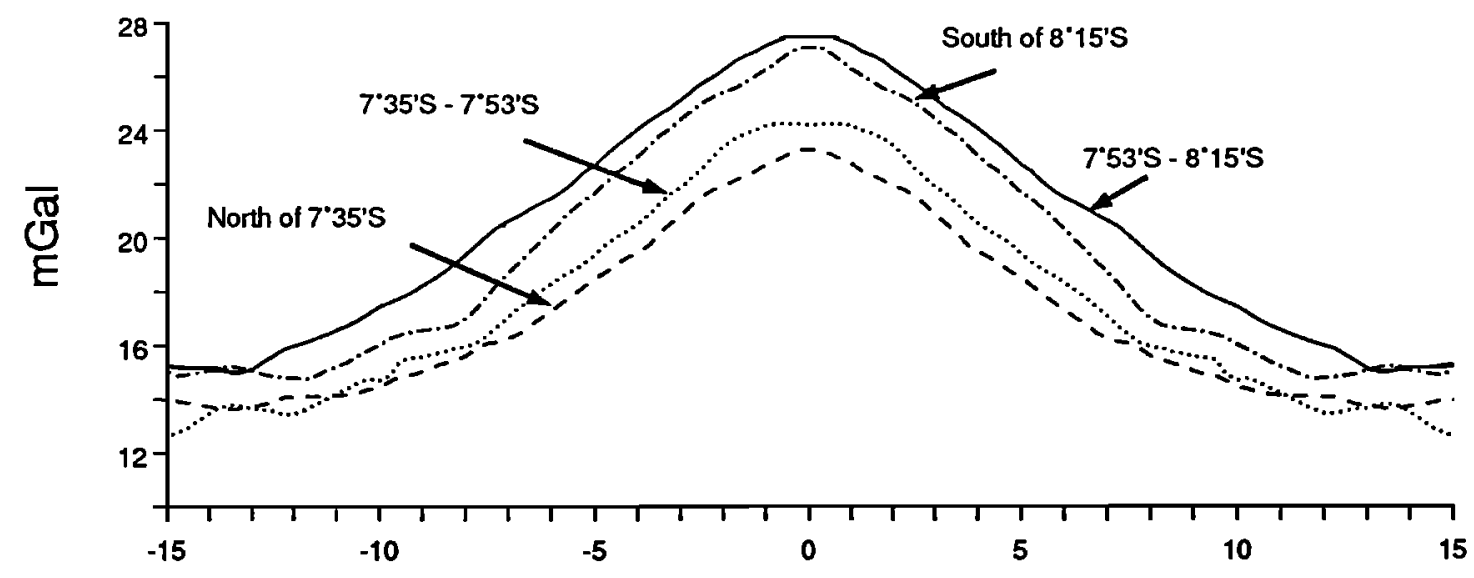

(b) Bathymetry

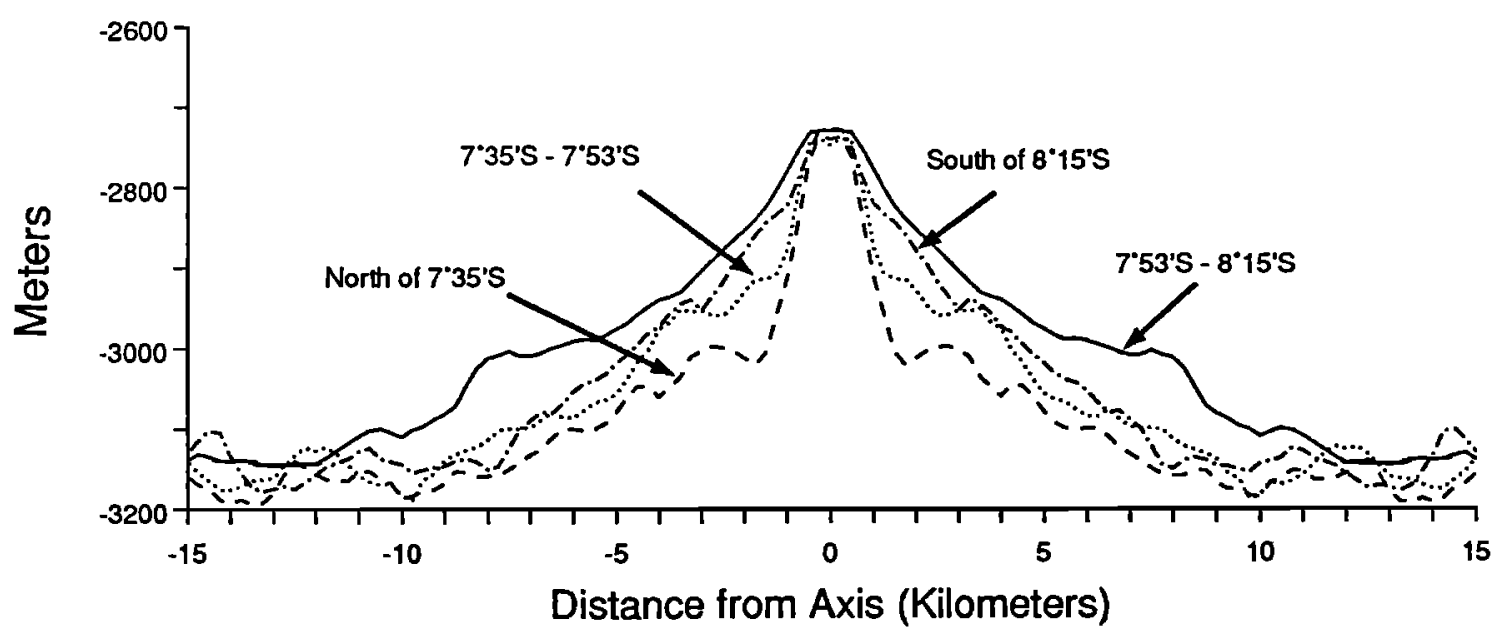

Fig. 7. (a) Stacked and mirrored crestal free-air gravity and (b) bathymetry profiles from four portions of the $7^{\circ} 12^{\prime} S-8^{\circ} 38^{\prime} S$ ridge segment. Note marked change in the width and shape of the crestal bathymetric high along the ridge segment. Also note the constant axial depth and broad, flat summit along the entire segment. Amplitude of the gravity anomaly relative to values on the ridge flanks is about $12.5 \mathrm{mGal}$ in the center of the segment decreasing to $9.5 \mathrm{mGal}$ at the the northern end.

ric step at about $65 \mathrm{~km}$ from the axis where mean depths increase by $70 \mathrm{~m}$ over a distance of a few kilometers. The subsidence rate for distances of $68-100 \mathrm{~km}$ from the axis is $140 \pm 21$ $\mathrm{m} / \mathrm{m} . \mathrm{y} .{ }^{1 / 2}$. If the data are fit from 10 to $100 \mathrm{~km}$ from the axis, the best fitting subsidence rate is $215 \pm 7 \mathrm{~m} / \mathrm{m} . y^{1 / 2}$. Since bathymetric relief on the ridge flanks is subdued, these observed subsidence rates are quite well defined (Figure 8). The standard deviation of the bathymetry about the $70 \mathrm{~m} / \mathrm{m} . y .{ }^{1 / 2}$ subsidence curve from 10 to $64 \mathrm{~km}$ from the axis is only $19 \mathrm{~m}$, while the standard deviation about the $215 \mathrm{~m} / \mathrm{m} . y .^{1 / 2}$ subsidence curve from 10 to $100 \mathrm{~km}$ from the axis is $28 \mathrm{~m}$.

The observed subsidence rates are much lower than the normally quoted worldwide average of about $350 \mathrm{~m} / \mathrm{m} . \mathrm{y} .{ }^{1 / 2}$ [Parsons and Sclater, 1977; Stein and Stein, 1992]. However, the value of $215 \mathrm{~m} / \mathrm{m} . \mathrm{y}^{1 / 2}$ is consistent with other determinations from the southern EPR, which range as low as 186 $\mathrm{m} / \mathrm{m} . y^{1 / 2}$ [Cochran, 1986]. By utilizing two subsidence rates $\left(70 \mathrm{~m} / \mathrm{m} . \mathrm{y}^{1 / 2}\right.$ and $\left.215 \mathrm{~m} / \mathrm{m} . \mathrm{y}^{1 / 2}\right)$, we can test the sensitivity of the results to the choice of a particular subsidence curve over a wide range of subsidence rates which produce reasonable fits to the ridge flank depths. Subsidence rates much greater than 215 $\mathrm{m} / \mathrm{m}$.y. ${ }^{1 / 2}$ simply do not describe the ridge flank subsidence observed in this region. A subsidence rate of $350 \mathrm{~m} / \mathrm{m} . y^{1 / 2}$ predicts $283 \mathrm{~m}$ of subsidence from $10 \mathrm{~km}(0.139 \mathrm{Ma})$ to 100 $\mathrm{km}(1.39 \mathrm{Ma})$ from the axis which is $100 \mathrm{~m}$ more than observed (Figure 8).

Free-air gravity anomaly profiles calculated for subsidence rates of 70 and $215 \mathrm{~m} / \mathrm{m} . \mathrm{y}^{1 / 2}$ are shown in Figure 8 along with a stacked, mirrored gravity profile obtained from the complete set of gravity profiles. The theoretical gravity profiles were calculated by the technique of Ockendon and Turcotte [1977], following the procedure developed by Haxby and Turcotte [1978] for geoid anomalies across mid-ocean ridges. A halfspace cooling model [Parker and Oldenburg, 1973; Davis and Lister, 1974] was used in the gravity calculations. Values assumed for lithospheric parameters in the calculations are listed in Table 1. We removed the effects of the thermal subsidence from the observed profiles for the four portions of the ridge axis using subsidence rates of 70 and $215 \mathrm{~m} / \mathrm{m} . \mathrm{y}^{1 / 2}$ to obtain residual topography and gravity profiles. We interpret these 


\section{(a) Gravity}

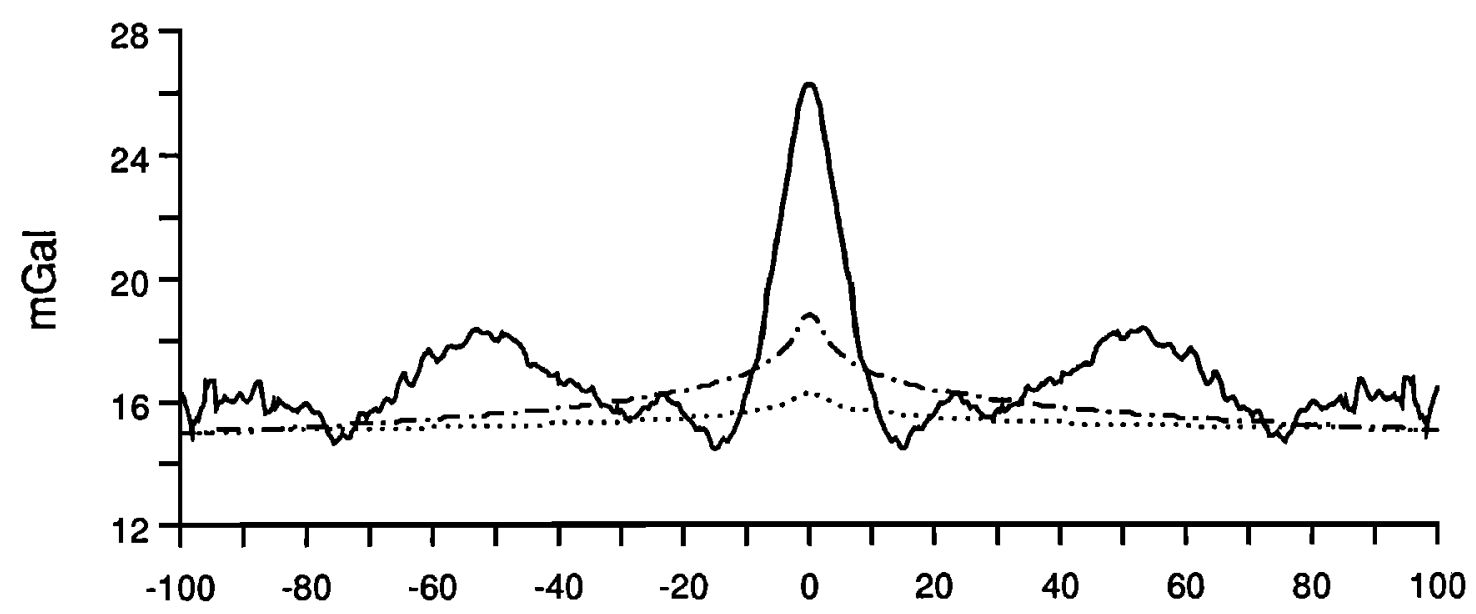

(b) Bathymetry

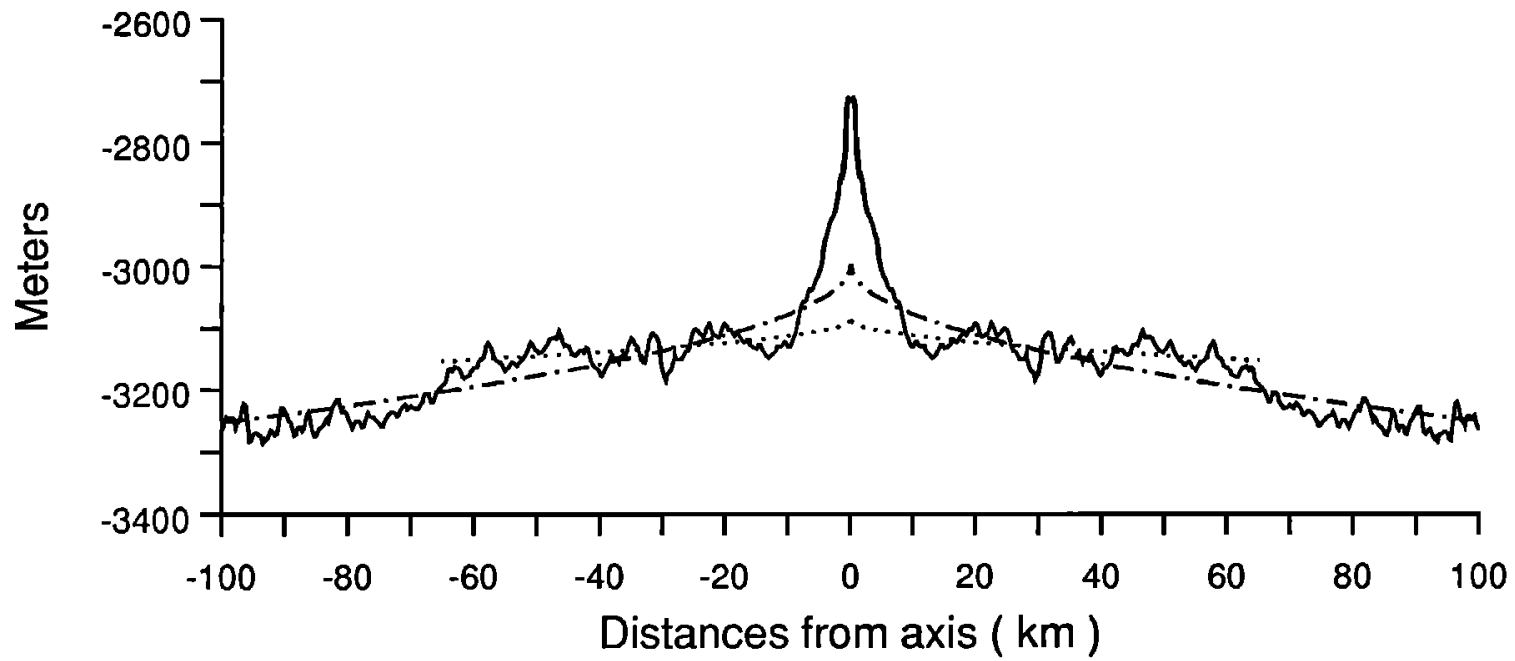

Fig 8. (a) Stacked and mirrored free-air gravity and (b) bathymetry profiles for the entire $7^{\circ} 12^{\prime} S-8^{\circ} 38^{\prime} S$ ridge segment compared with two thermal subsidence curves. The dotted bathymetry curve shows the best fitting square root of age curve for distances of 10-64 km from the axis $\left(C_{1}=70 \mathrm{~m} / \mathrm{m} . y .1 / 2\right)$ and the dash-dotted curve the best fitting square root of age curve for distances of 10-100 km from the axis $\left(C_{1}=215 \mathrm{~m} / \mathrm{m} . y .{ }^{1 / 2}\right)$. The corresponding gravity curves show free-air gravity anomalies calculated from a cooling half-space model with the appropriate subsidence rate.

residual profiles as representing the response of the lithosphere to a low-density region beneath the ridge axis.

We model the crestal high as a flexural feature resulting from the upward "load" of a region of low density material centered beneath the ridge axis as suggested by Madsen $e t$ al. [1984]. In a flexural model, the lithospheric plate can be considered either to be continuous or to be broken at the axis. Analyses of gravity and bathymetric data at the crest of the EPR by Madsen et al. [1984] and Kuo et al. [1986] indicate that the flexural rigidity is very low at the axis and increases away from the ridge crest as the plate cools and thickens. We will thus utilize a broken plate model in this study. In addition, the fact that the crestal high has a broad, flat summit and the axial depth is essentially constant along the entire length of the $7^{\circ} 12^{\prime} \mathrm{S}-8^{\circ} 38^{\prime} \mathrm{S}$ ridge segment (Figure 3 ) in spite of the great variation in the shape and width of the crestal bathymetric high (Figures 2, 4, and 5) suggests that material ascending at the ridge axis is able to reach a constant depth relatively uninhibited by the strength of the overlying plate. We therefore consider the immediate vicinity of the axis to be locally compensated and place the edge of the broken plate at a distance of 0.5 $\mathrm{km}$ from the axis.

The deflection $w$ of an elastic plate subjected to an imposed load is governed by the biharmonic equation

$$
d^{2}\left[D(x) d^{2} w / d x^{2}\right] / d x^{2}+\Delta \rho g w=p(x)
$$

where $D(x)$ is the flexural rigidity, $\Delta \rho$ is density difference between the mantle and seawater, $g$ is the gravitational accelera- 
TABLE 1. Values of Model Parameters

\begin{tabular}{|c|c|c|}
\hline Parameters & Symbol & Value \\
\hline $\begin{array}{l}\text { Gravitational constant } \\
\text { Gravitational acceleration } \\
\text { Young's modulus } \\
\text { Poisson's ratio } \\
\text { Density of seawater } \\
\text { Density of crust } \\
\text { Density of mantle } \\
\text { Plate thickness } \\
\text { Asthenospheric temperature } \\
\text { Thermal conductivity } \\
\text { Coefficient of thermal expansion }\end{array}$ & $\begin{array}{l}\mathbf{G} \\
\mathbf{G} \\
\mathbf{E} \\
\sigma \\
\rho_{\mathbf{w}} \\
\rho_{\mathbf{c}} \\
\rho_{\mathbf{m}} \\
\mathbf{H} \\
\mathbf{T} \\
\mathbf{k} \\
\alpha\end{array}$ & $\begin{array}{l}6.673 \times 10^{11} \mathrm{~N} \mathrm{~m}^{2} \mathrm{~kg}^{2} \\
980 \mathrm{~cm} \mathrm{~s}^{-2} \\
1 \times 10^{12} \mathrm{~N} \mathrm{~m}^{-2} \\
0.25 \\
1030 \mathrm{~kg} \mathrm{~m}^{3} \\
2730 \mathrm{~kg} \mathrm{~m}^{3} \\
3330 \mathrm{~kg} \mathrm{~m}^{3} \\
125 \mathrm{~km}^{\circ} \\
1350^{\circ} \mathrm{C} \\
0.008 \mathrm{cal}^{\circ} \mathrm{C}^{1} \mathrm{~cm}^{-1} \mathrm{~s}^{-1} \\
3.2 \times 10^{5}{ }^{\circ} \mathrm{C}^{-1}\end{array}$ \\
\hline
\end{tabular}

tion and $p(x)$ is the imposed load. The appropriate boundary conditions for a broken plate are that $d^{2} w / d x^{2}=d^{3} w / d x^{3}=0$ at the free edge $(x=0)$ and that $w=d w / d x=0$ at $x=\infty$.

The fact that the flexural rigidity $D$ is considered to be a function of position in equation (1) and thus is not brought outside the differentiation allows us to consider the case in which the flexural rigidity changes with distance from the ridge axis. However, as pointed out by Kuo et al. [1986], material added to the base of the plate as it moves away from the axis is initially stress free, which is not the assumption if equation (1) is used. Equation (1) describes the case in which a plate acquires a given flexural rigidity distribution and is then flexed. Kuo et al. [1986] derived an expression for a growing plate in which $D$ monotonically increases with distance. That expression is

$$
d\left[D(x) d^{3} w / d x^{3}\right] / d x+\Delta \rho g w=p(x)
$$

where the boundary conditions are the same as for equation (1). In the model calculations which assume a growing plate, we solve equation (2) using a five-point finite difference technique.

Interpretation of bathymetry and gravity data in terms of loading from below is complicated by the fact that the load is not observed. Thus it is necessary not only to determine the lithospheric flexural parameters, as in the case of loading from above, but also to deduce the nature of the subsurface buoyant mass responsible for the deformation. We do this as a two-step process. We first use the residual bathymetry data to determine the flexural rigidity and the amount and horizontal distribution of the buoyant material. This is possible because the deformation of the lithosphere is controlled by the upward buoyant force on the base of the lithosphere and does not depend on the exact distribution with depth of the material responsible for this force. We then use the gravity data to determine the depth distribution of the anomalous mass.

We assumed that within $0.5 \mathrm{~km}$ of the axis the residual crestal bathymetric high has a constant height and is underlain by a mass deficiency sufficient to locally compensate the residual axial elevation. The upward force on the free end of the broken plate is equal to that of a mass column necessary to locally support the axis. The buoyant force is assumed to decrease linearly away from the edge of the plate. We investigated both the case where the effective elastic plate thickness $T_{e}$ is a constant and the case where it is assumed to be of the form

$$
T_{e}(x)=R x^{I / 2}+T_{e}(0)
$$

where $x$ is distance from the edge of the broken plate, $R$ is the plate thickening rate $\left(\mathrm{km}^{1 / 2}\right)$ and $T_{e}(0)$ is taken as $0.1 \mathrm{~km}[K u o$ et al., 1986]. $T_{e}$ is related to the flexural rigidity $D$ by

$$
D=E T_{e}^{3} / 12\left(1-\sigma^{2}\right)
$$

where $E$ is Young's modulus, and $\sigma$ is Poisson's ratio.

We determined the best fitting elastic plate thickness $T_{\mathrm{e}}$ (or plate thickening rate $R$ ) and the load width $X$ by systematically varying these parameters and determining the rms misfit between the observed residual topography and calculated deflection profiles for a distance of $30 \mathrm{~km}$ from the axis. The zero level of the residual topographic profiles was adjusted prior to fitting so that the average value at distances of $12-30 \mathrm{~km}$ from the axis is zero.

The results of fitting the residual topographic profiles are shown in Figures 9 and 10, and the results are listed in Tables 2 and 3. Figure 9 shows the rms misfit of the calculated deflection to the observed residual topographic profiles as a function of $T_{e}$ (or $R$ ) and $X$. For each section of the ridge crest, residual topographic curves obtained assuming both a subsidence rate $C_{1}$ of 70 and of $215 \mathrm{~m} / \mathrm{m}$.y. ${ }^{1 / 2}$ were fit. Flexure curves calculated from the best fitting rigidity and load width are compared to the residual topography profiles in Figure 10. Figures 9a and $10 \mathrm{a}$ show the results for the case of a constant rigidity plate, while Figures $9 \mathrm{~b}$ and $10 \mathrm{~b}$ show the case in which the rigidity increases with the age of the plate.

The best fitting values of $T_{e}$ for the constant rigidity case (Table 2) are in the range of $0.4-0.6 \mathrm{~km}$ for $C_{l}=70 \mathrm{~m} / \mathrm{m} . \mathrm{y} .^{1 / 2}$, and $0.3-0.5 \mathrm{~km}$ for $C_{l}=215 \mathrm{~m} / \mathrm{m} . y^{1 / 2}$. For the growing plate model, the best fitting values of $R$ are $0.2 \mathrm{~km}^{1 / 2}$ for $C_{l}=70$ $\mathrm{m} / \mathrm{m} . \mathrm{y} .1 / 2$, and in the range of $0.2-0.3 \mathrm{~km}^{1 / 2}$ for $C_{1}=215$ $\mathrm{m} / \mathrm{m} . \mathrm{y}^{1 / 2}$. For a constant rigidity plate, the $\mathrm{ms}$ misfits show a well-defined minimum. The constraints on the size of the load are stronger than those on the rigidity, and the variation in the width (i.e., size) of the load along the axis is quite robust (Figure 9). The ms misfits for the growing plate model do not have as well defined of a minimum but rather have a shallow trough in which a range of combinations of $X$ and $R$ provide fairly similar fits to the data (Fig. 9). In all of the models examined, the amplitude of the mass deficiency necessary to support the crestal high is clearly a maximum between $7^{\circ} 53$ 'S and $8^{\circ} 15^{\prime} S$ and decreases steadily toward the ends of the ridge segment.

The second step is to use the residual gravity anomalies to determine the depth distribution of the density anomaly represented by the buoyant force. We assumed that the top of the low-density region under the ridge axis is given by the prominent, high amplitude reflector observed under the ridge axis of the EPR in seismic reflection studies [e.g., Herron et al., 1978, 

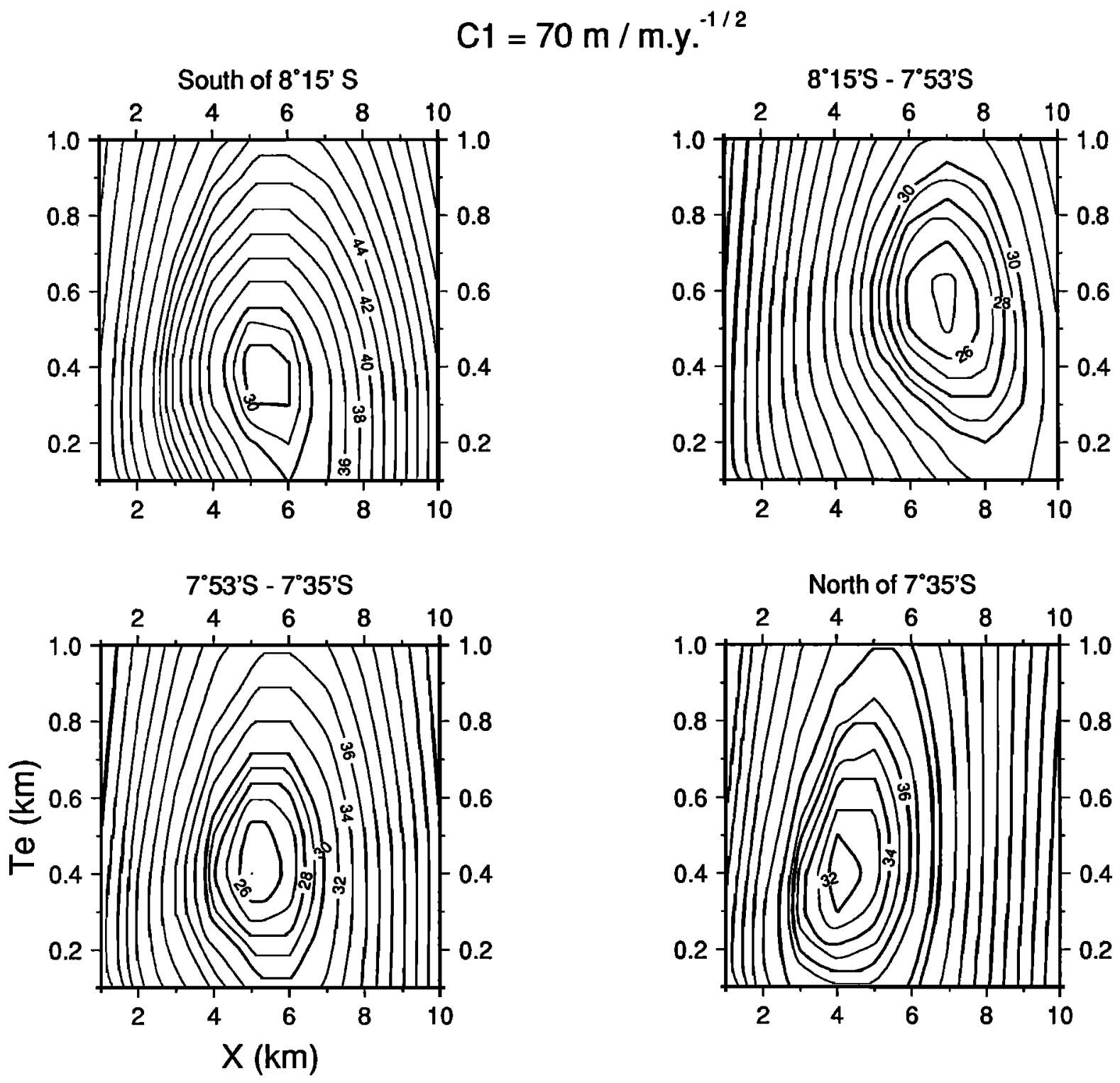

Fig. 9a. The rms misfit between constant rigidity (static) plate models and residual axial topography for four portions of the $7^{\circ} 12^{\prime} \mathrm{S}-8^{\circ} 38^{\prime} \mathrm{S}$ ridge segment. Misfit was determined for a variety of choices of load width $X$ and effective elastic plate thickness $T$. Calculations were carried out for residual bathymetric profiles determined using subsidence rates of 70 and 215 $\mathrm{m} / \mathrm{m} . \mathrm{y} \cdot 1 / 2$.

1980; Hale et al., 1982; Detrick et al., 1987], which is widely interpreted to mark the top of an axial magma chamber or melt lens. In the absence of seismic data from our field area, we will assume that the top of the low-density region under the ridge axis is at a depth of $4.0 \mathrm{~km}$ below the sea surface, about $1.3 \mathrm{~km}$ below the seafloor. This is consistent with recent seismic data from $15^{\circ} \mathrm{S}$ [Detrick et al., 1991], where the spreading rate is similar to that in our field area. We assume a constant density anomaly $\Delta \rho$ and that the base of the low density region is horizontal. Therefore, at distances of greater than $0.5 \mathrm{~km}$ from the axis, the depth to the top of the low-density region increases linearly with distance from the axis.

The gravity effect of the low-density body was calculated using the two-dimensional line integral technique of Talwani et al. [1959]. We systematically varied $\Delta \rho$, and thus the depth $Z$ to which the density anomaly extends, to obtain the best fit to the observed residual gravity anomalies. The zero level of the residual gravity anomalies was adjusted by a d.c. shift so that the average value of the residuals from 12 to $30 \mathrm{~km}$ from the axis is $0 \mathrm{mGal}$. The rms misfit as a function of $Z$ (and equivalently as a function of $\Delta \rho$ ) is shown in Figure 11 and the calculated best fit gravity is compared to the observed residual anomalies in Figure 12.

The best fit to the residual gravity anomalies for $C_{1}=70$ $\mathrm{m} / \mathrm{m} . \mathrm{y} \cdot{ }^{1 / 2}$ occurs when the base of the low density area is at depths of $22-31 \mathrm{~km}$ for the constant rigidity plate and at $17-22$ $\mathrm{km}$ for the growing plate. The misfit increases rapidly as the base of the low-density region is brought shallower than about $20 \mathrm{~km}$. The calculated gravity anomalies are a very good match to the observed residual gravity profiles, particularly within 15 $\mathrm{km}$ of the axis in the region of the crestal high. The fit to the data is consistently better, both statistically and visually for $C_{1}=70 \mathrm{~m} / \mathrm{m} . \mathrm{y} .{ }^{1 / 2}$ than for $C_{1}=215 \mathrm{~m} / \mathrm{m}$.y. ${ }^{1 / 2}$. Note that the $C_{l}=215 \mathrm{~m} / \mathrm{m}$. . $^{1 / 2}$ residual gravity profiles decrease by about $1 \mathrm{mGal}$ at the axis for all four sections of the ridge axis. This suggests that we are overestimating the effect of thermal subsidence in calculating those residual gravity profiles and that the proper value for $C_{1}$ is actually less than $215 \mathrm{~m} / \mathrm{m} . y^{1 / 2}$. We 


$$
\mathrm{C} 1=215 \mathrm{~m} / \mathrm{m} \cdot \mathrm{y} .^{-1 / 2}
$$
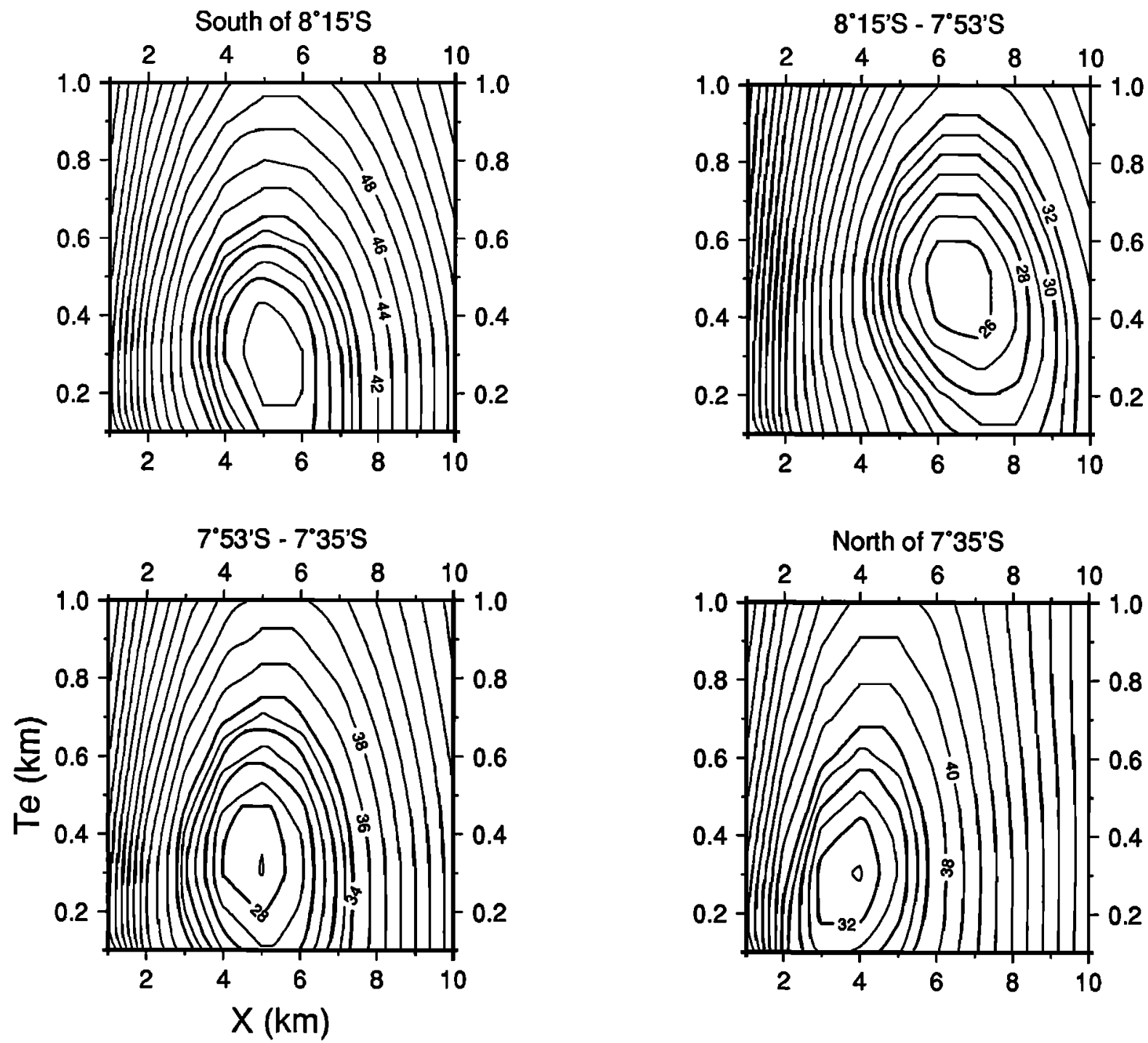

Fig. 9a. (continued)

therefore take the $70 \mathrm{~m} / \mathrm{m} . y_{.}{ }^{1 / 2}$ results as our preferred solution.

The minimum rms misfit for the region to the south of $8^{\circ} 15^{\prime} \mathrm{S}$ is consistently a factor of 2 greater than for the other three regions. Also, the compensation depth determined for the region south of $8^{\circ} 15^{\prime} \mathrm{S}$ is consistently several kilometers shallower than for the other three regions. These results are due to the presence of lineated topographic highs and their associated gravity high at about $17-27 \mathrm{~km}$ from the axis on both flanks, which are not completely eliminated by stacking the profiles. The residual gravity high between 20 and $30 \mathrm{~km}$ from the axis apparently results in setting the zero level slightly too high, decreasing the amplitude of the crestal residual gravity anomaly and thus also decreasing the compensation depth. The compensation depths for the other three regions are closely grouped in the range of $25-31 \mathrm{~km}$ for the constant rigidity plate and $20-22 \mathrm{~km}$ for the growing plate model. Compensation depths determined for $C_{l}=215 \mathrm{~m} / \mathrm{m} . y{ }^{1 / 2}$ are quite similar. The range is $26-30 \mathrm{~km}$ for the constant rigidity plate and $23-29 \mathrm{~km}$ for the growing plate model. The similarity of depth to which the low density region must extend for $C_{I}=70 \mathrm{~m} / \mathrm{m} . \mathrm{y} \cdot{ }^{1 / 2}$ and $C_{1}=215 \mathrm{~m} / \mathrm{m} . \mathrm{y} .^{1 / 2}$ demonstrates that our results are not sensitive to the details of the thermal model over a wide range of subsidence rates.

The sensitivity of the gravity anomalies to the depth to which the anomalous mass extends is examined in Figure 13. Figure 13 shows the $7^{\circ} 53^{\prime} \mathrm{S}-8^{\circ} 15^{\prime} \mathrm{S}$ residual gravity profile for for the constant rigidity plate model with $C_{1}=70 \mathrm{~m} / \mathrm{m} . \mathrm{y} .1 / 2$ along with calculated gravity anomalies resulting when the low-density region is assumed to extend to different depths beneath the ridge crest. The amplitude of the mass anomaly and the lateral distribution of anomalous mass are the same in each case and are those necessary to fit the residual bathymetry (Fig. 11 and Table 2). The best fit to the gravity data occurs when the base of the low-density region is located at a depth of 25 $\mathrm{km}$. As the mass is brought to shallower depths, the calculated ridge crest gravity anomaly decreases rapidly in amplitude, so that it is less than $8 \mathrm{mGal}$ when the base of the mass anomaly is at $15 \mathrm{~km}$ and is only $6 \mathrm{mGal}$ when the base of the mass anomaly is as shallow as $10 \mathrm{~km}$. The gravity data thus provide good resolution on depth to which the low-density region must extend. In particular, the predicted gravity anomaly rapidly becomes much smaller than the observed gravity anomaly when the base of the low-density region is brought to depth of less than about $20 \mathrm{~km}$. 


$$
\mathrm{C} 1=70 \mathrm{~m} / \mathrm{m}_{\mathrm{y}} \mathrm{y}^{-1 / 2}
$$
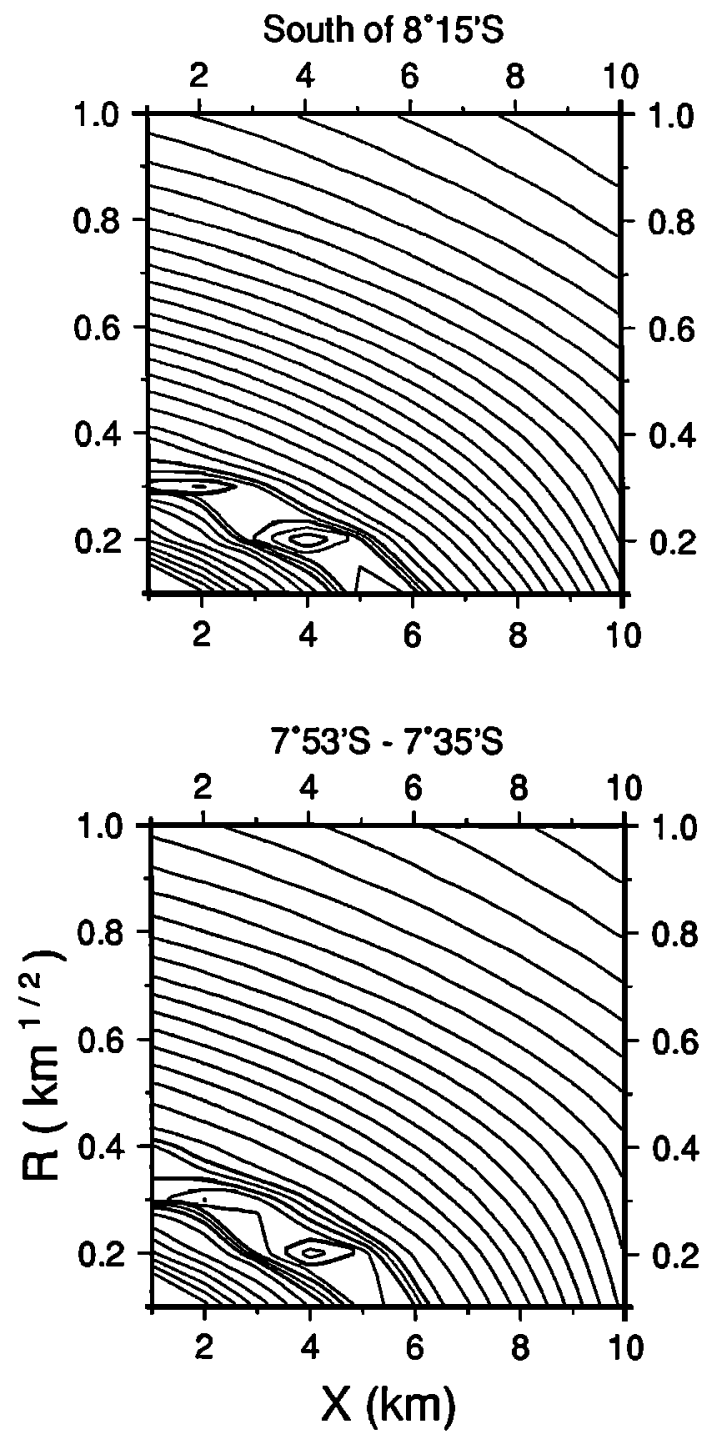
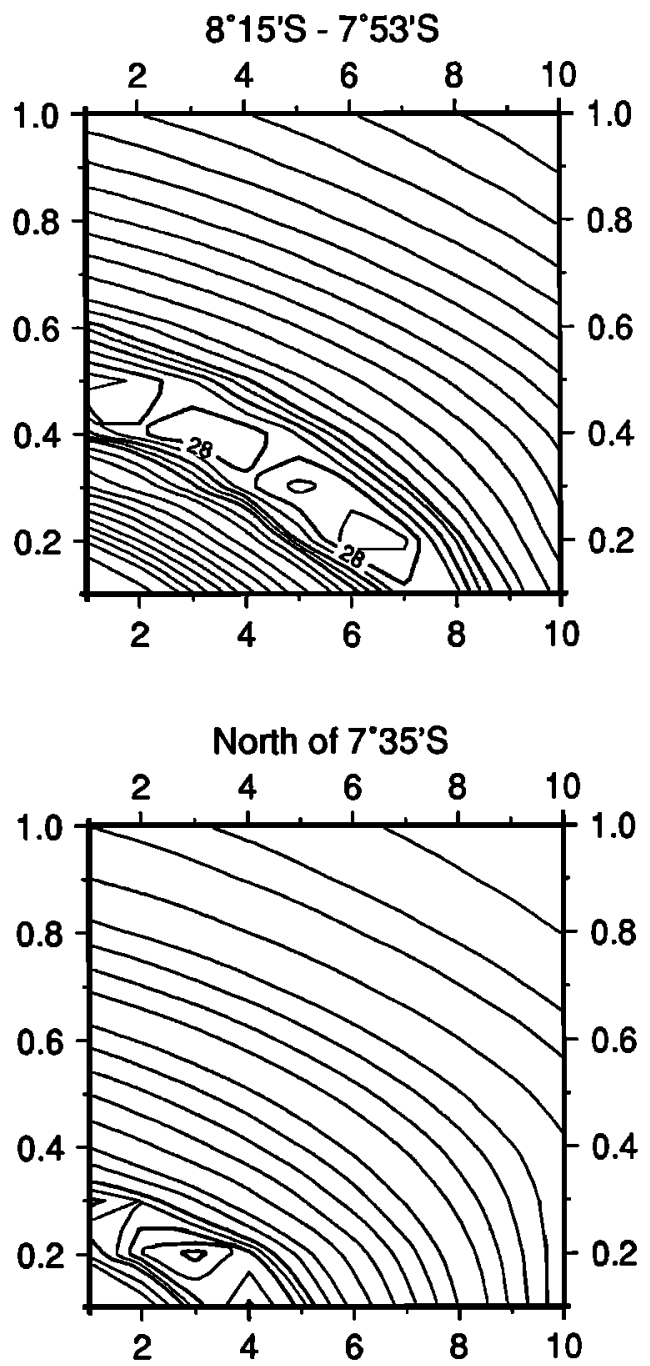

Fig. 9b. The rms misfit between growing plate [Kuv el al., 1986] models and residual axial topography for four portions of the $7^{\circ} 12^{\prime} \mathrm{S}-8^{\circ} 38^{\prime} \mathrm{S}$ ridge segment. Misfit was determined for a variely of choices of load width $X$ and plate thickening rate $R$. Calculations were carried out for residual balhymetric profiles determined using subsidence rates of 70 and $215 \mathrm{~m} / \mathrm{m}$.y.112.

The depth to which the anomalous mass must extend is not extremely sensitive to the exact shape of the low-density region. In addition to the case where the upward buoyant force decreases linearly away from the axis, we also investigated the cases where it falls off both parabolically and as $\left(1-\left(\mathrm{x}_{\mathrm{i}} / \mathrm{X}\right)^{1 / 2}\right)$. These models result in more of the anomalous mass being located near the base of the low-density region, and we therefore expected that the base of the anomalous area would have to be brought shallower to match the observed gravity. However, this effect was not very great. The best fit to the gravity anomalies for the $7^{\circ} 53^{\prime} \mathrm{S}-8^{\circ} 15^{\prime} \mathrm{S}$ region for the constant rigidity plate model with $C_{l}=70 \mathrm{~m} / \mathrm{m}$.y. ${ }^{1 / 2}$ were $21.5 \mathrm{~km}$ for the (1$\left.\left(\mathrm{x}_{\mathrm{i}} / \mathrm{X}\right)^{1 / 2}\right)$ model and $23 \mathrm{~km}$ for the parabolic model. These are not significantly different from the depth of $25 \mathrm{~km}$ determined for the linear model (Table 2). It thus appears that our conclusion that the low density region must extend to a depth of at least $20 \mathrm{~km}$ is quite robust.

The compensation depths reported by Madsen et al. [1984] for the crestal bathymetric bigh (6-7 $\mathrm{km}$ below the seafloor or $9-10 \mathrm{~km}$ below the observation level) are significantly shal- lower than the depths of $20-31 \mathrm{~km}$ which we obtained. One reason for this difference is that Madsen et al. [1984] did not actually determine compensation depths in the classical sense that all of the compensation occurs above that depth. Rather what they determined is the depth to the center of mass of the compensating body. We also show the depth to the center of mass of the low density region for our best fitting models in Tables 2 and 3. These depths (14-19 km) are shallower but are still somewhat greater than those determined by Madsen et al. [1984]. A second difference between our calculations and those of Madsen et al. [1984] is that Madsen et al. did not remove the effects of thermal contraction away from the ridge axis from either their bathymetry or gravity profiles. However, for the low subsidence rate of our preferred model $\left(C_{1}=70 \mathrm{~m} / \mathrm{m} . .^{1 / 2}\right)$, this does not greatly effect the results.

There are also some problems with the data set used by Madsen et al. [1984], at least in the $6^{\circ} \mathrm{S}-11^{\circ} \mathrm{S}$ area. Madsen et al.'s profile 4 shows an approximately $5-\mathrm{mGal}$ anomaly over the ridge crest, while the data from that same cruise in our database show a $12 \mathrm{mGal}$ anomaly. Their profile 4 crosses the 


$$
\mathrm{C} 1=215 \mathrm{~m} / \mathrm{m} \cdot \mathrm{y} .^{-1 / 2}
$$
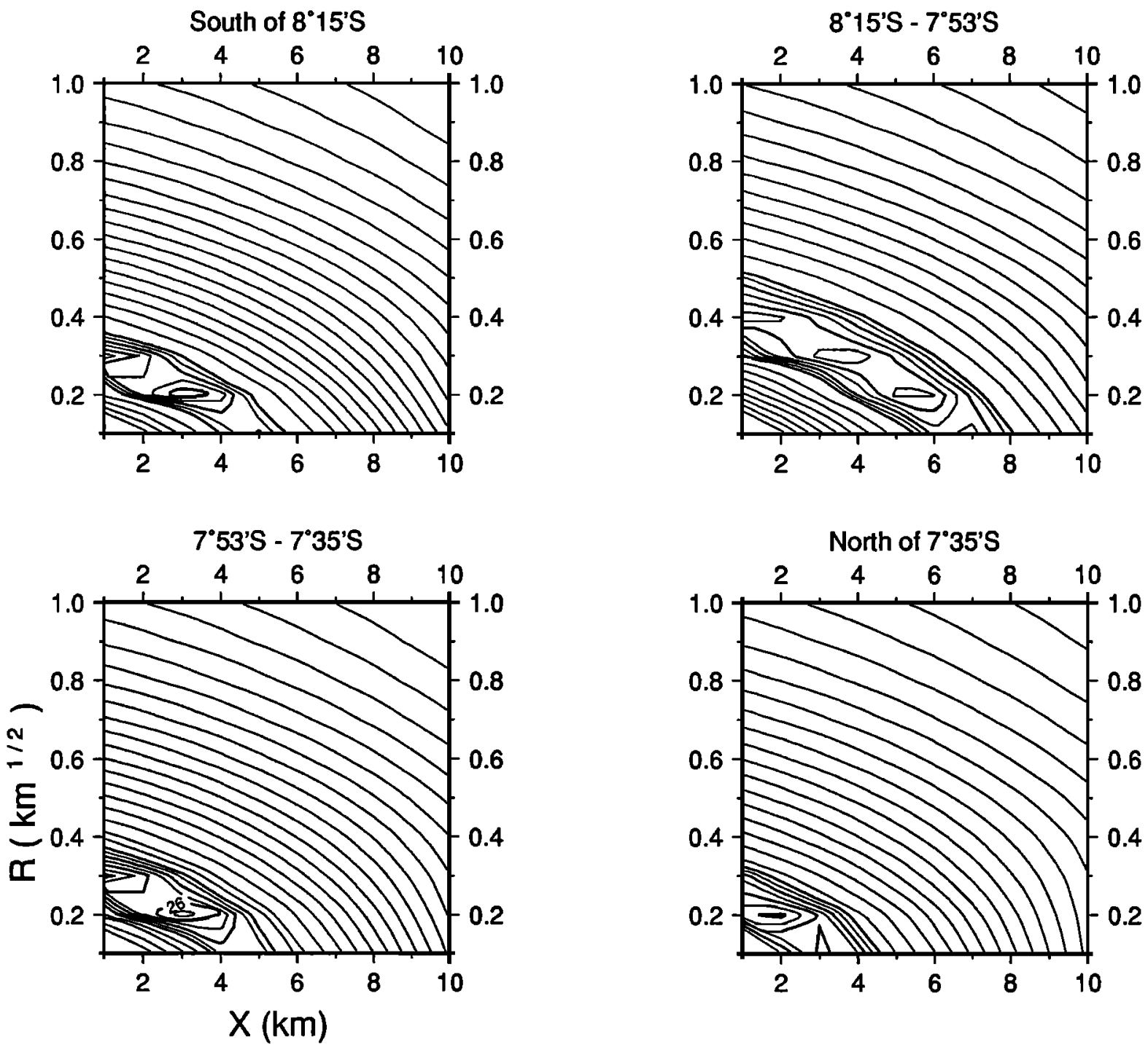

Fig. 9b. (continued)

ridge axis at the location of our line 44 (Figure 1) which also shows a $12-\mathrm{mGal}$ anomaly in agreement with our version of the data (Figure 6). Also, Madsen et al.'s profile 3 crosses the axis at the $7^{\circ} 12$ 'S OSC and is clearly disturbed. If the data which they used in the $6^{\circ} \mathrm{S}-11^{\circ} \mathrm{S}$ area are stacked, omitting profile 3 and using the correct values for profile 4 , the resulting profile shows an $11-\mathrm{mGal}$ high over the axis rather than the $8-\mathrm{mGal}$ high in Madsen et al.'s stacked profile. The larger gravity anomaly requires the compensating mass to be deeper. We fit the edited version of Madsen et al.'s $6^{\circ} \mathrm{S}-11^{\circ} \mathrm{S}$ data set using a constant rigidity plate which is assumed to be broken at the ridge axis, as in their models. The center of mass of the best fitting buoyant low-density region was at a depth of $12.3 \mathrm{~km}$ with the mass deficiency extending to a depth of $19 \mathrm{~km}$. These results are similar to those which we obtained from our detailed data set.

\section{DISCUSSION}

One very robust conclusion of our model studies is that the buoyant mass supporting the crestal bathymetric high is not located in the crust nor centered near the crust-mantle boundary but extends for a considerable distance into the mantle. The mass deficiency must extend to depths in the range of $20-31 \mathrm{~km}$ below the sea surface for both choices of thermal subsidence rate and for all four sections of the ridge axis. Wilson [1992] modeled the crestal high on stacked profiles across the northerm EPR and the Juan de Fuca Ridge as locally compensated and concluded that the depth of compensation is in the range of 15$50 \mathrm{~km}$.

The most reasonable explanation for a region of low-density material centered at the ridge axis and extending to a depth of $20-30 \mathrm{~km}$ below the sea surface is that it represents a region of partial melt feeding magma to the ridge axis. The density as a function of temperature $T$ and melt fraction $\phi$ is given by

$$
\rho=\rho_{0}\left(1-\alpha\left(T-T_{0}\right)-\gamma \phi\right)
$$




$$
\mathrm{C} 1=70 \mathrm{~m} / \mathrm{m} . \mathrm{y} .^{-1 / 2}
$$
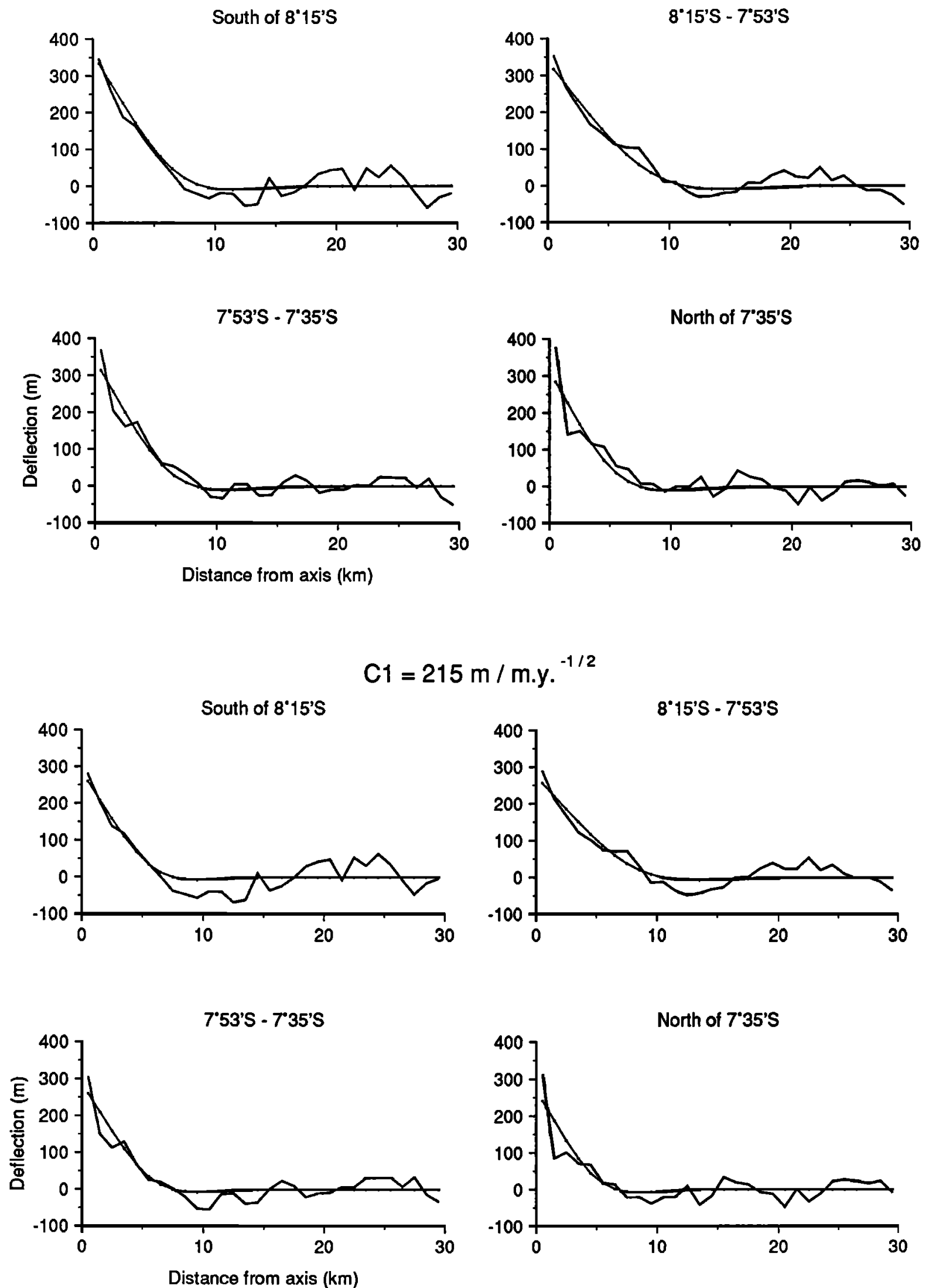

Fig. 10a. Comparison of best fitting flexural curves to residual bathymetric profiles for four portions of the $7^{\circ} 12^{\prime} \mathrm{S}-8^{\circ} 38^{\prime} \mathrm{S}$ ridge segment for a constant rigidity elastic plate model. Parameters used in the flexural calculation are shown in Table 3. Calculations were carried out for residual bathymetric profiles determined using subsidence rates of 70 and $215 \mathrm{~m} / \mathrm{m} . \mathrm{y}^{1} \mathbf{1}_{1 / 2}$. 


$$
\mathrm{C} 1=70 \mathrm{~m} / \mathrm{m}_{\mathrm{y}} .^{-1 / 2}
$$

South of $8^{\circ} 15^{\prime} S$

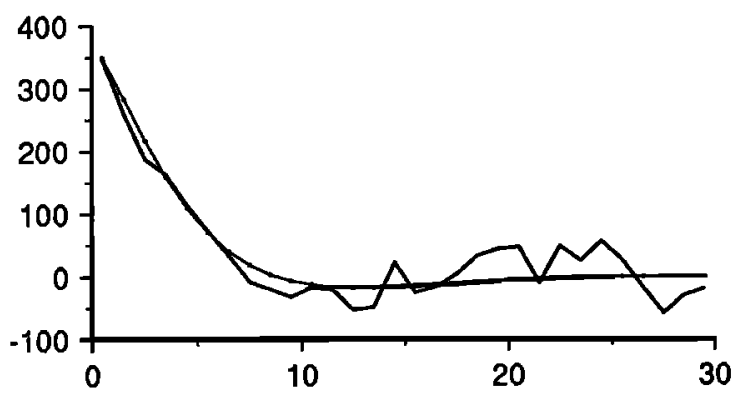

$8^{\prime} 15^{\prime} \mathrm{S}-7^{*} 53^{\prime} \mathrm{S}$

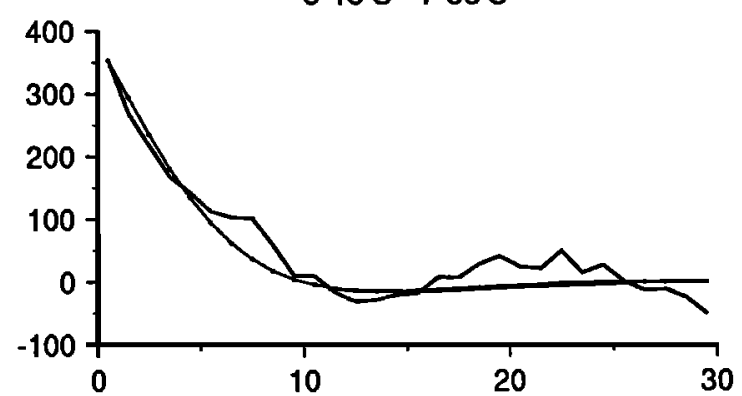

7־53'S - 7’35'S
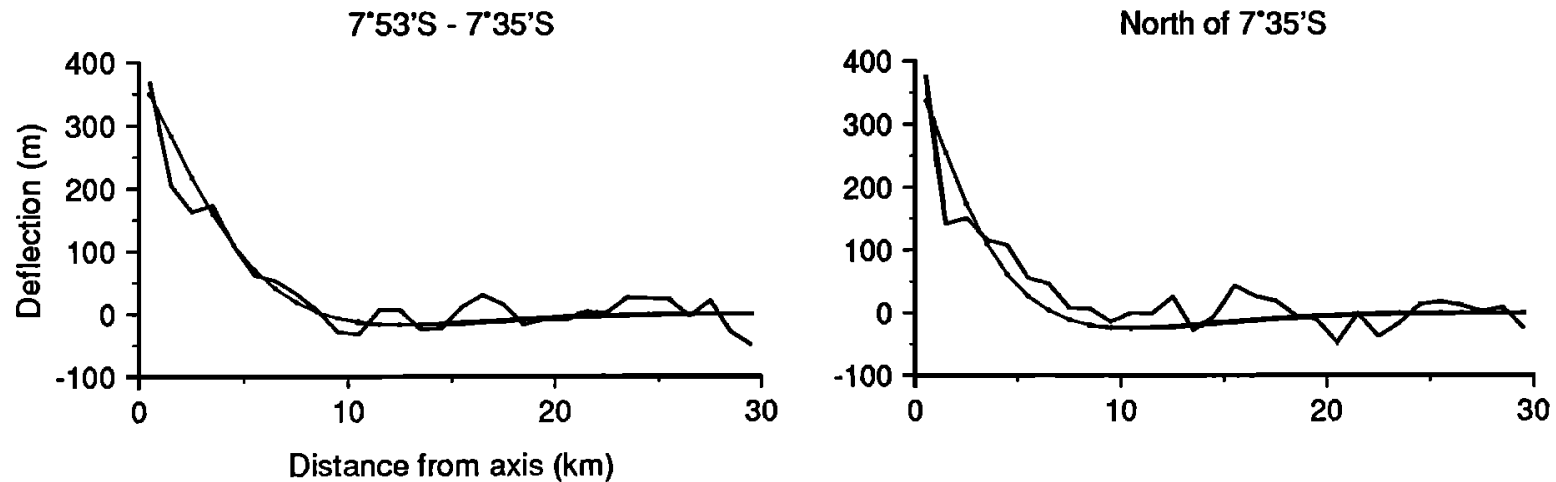

$$
\mathrm{C} 1=215 \mathrm{~m} / \mathrm{m} \cdot \mathrm{y} .^{-1 / 2}
$$

South of $8^{*} 15^{\prime} \mathrm{S}$
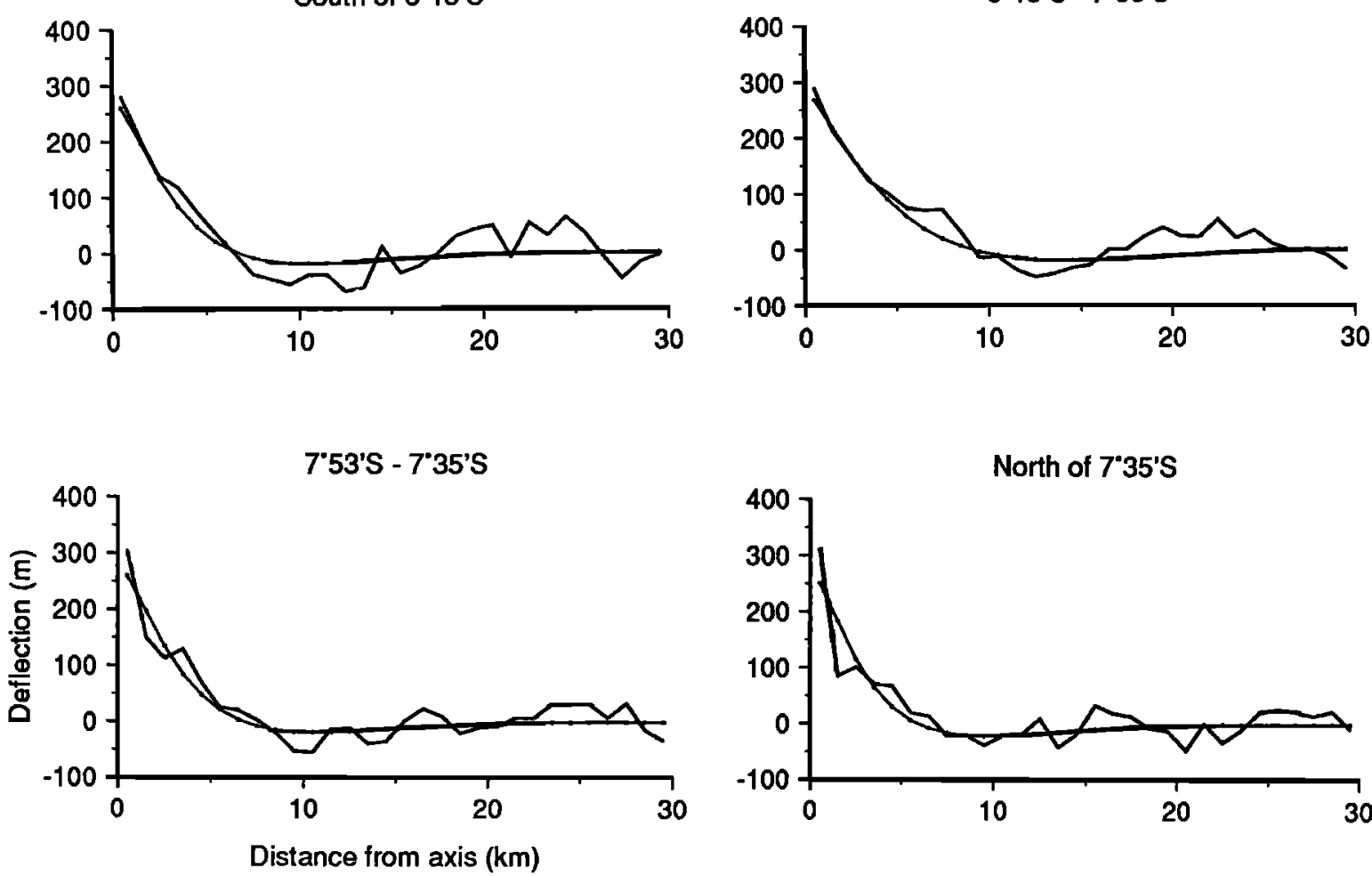

Fig. 10b. Comparison of best fitting flexural curves to residual bathymetric profiles for four portions of the $7^{\circ} 12^{\prime} \mathrm{S}-8^{\circ} 38^{\prime} \mathrm{S}$ ridge segment for a growing elastic plate model. Parameters used in the flexural calculation are shown in Table 3 . Calculations were carried out for residual bathymetric profiles determined using subsidence rates of 70 and $215 \mathrm{~m} / \mathrm{m} . \mathrm{y} .1 / 2$. 
TABLE 2. Model Results: Constant Rigidity (Static) Plate

\begin{tabular}{|c|c|c|c|c|c|c|c|}
\hline Segments & $\mathrm{R}, \mathrm{km}^{1 / 2}$ & $\mathrm{X}, \mathrm{km}$ & $\Delta \rho, g / \mathrm{cm}^{3}$ & $\mathbf{Z}, \mathbf{k m}$ & $\begin{array}{l}\text { Center of } \\
\text { Mass, km }\end{array}$ & $\begin{array}{l}\text { Mass Anomaly, } \\
10^{12} \mathrm{~kg} / \mathrm{km}\end{array}$ & Melt, \% \\
\hline \multicolumn{8}{|c|}{$C 1=70 \mathrm{~m} \cdot \mathrm{y} \cdot 1 / 2$} \\
\hline South of $8^{\circ} 15^{\prime}$ & 0.4 & 6 & -0.045 & 22 & 14.0 & 5.7 & 8.4 \\
\hline $7^{\circ} 53^{\prime}-8^{\circ} 15^{\prime}$ & 0.6 & 7 & -0.039 & 25 & 15.7 & 6.6 & 7.4 \\
\hline $7^{\circ} 35^{\prime}-7^{\circ} 53^{\prime}$ & 0.4 & 5 & -0.033 & 29 & 18.0 & 5.0 & 6.2 \\
\hline North of $7^{\circ} 35^{\prime}$ & 0.4 & 4 & -0.030 & 31 & 19.0 & 4.1 & 5.6 \\
\hline \multicolumn{8}{|c|}{$C 1=215 \mathrm{~m} / \mathrm{m} . \mathrm{y} .1 / 2$} \\
\hline South of $8^{\circ} 15^{\prime}$ & 0.3 & 5 & -0.034 & 22.6 & 14.3 & 3.8 & 6.4 \\
\hline $7^{\circ} 53^{\prime}-8^{\circ} 15^{\prime}$ & 0.5 & 7 & -0.028 & 26.6 & 16.6 & 5.0 & 5.2 \\
\hline $7^{\circ} 35^{\prime}-7^{\circ} 53^{\prime}$ & 0.3 & 5 & -0.026 & 28.6 & 17.7 & 3.8 & 4.9 \\
\hline North of $7^{\circ} 35^{\prime}$ & 0.3 & 4 & -0.025 & 29.6 & 18.2 & 3.2 & 4.7 \\
\hline
\end{tabular}

where $\rho_{0}$ is the density at $T=T_{0}$ and $\phi=0, \alpha$ is the coefficient of thermal expansion, and $\gamma=\left(\rho_{0}-\rho_{m}\right) / \rho_{0}$. We take the reference temperature $T_{0}=0^{\circ} \mathrm{C}$ and $\rho_{0}=3330 \mathrm{~kg} / \mathrm{m}^{3}$. The density of the melt, $p_{m}$, is assumed to be $2800 \mathrm{~kg} / \mathrm{m}^{3}$ [Scott and Stevenson, 1989]. Equation (5) ignores density changes due to variations in the degree of depletion of the mantle.

The range of density anomalies which we have determined beneath the axis $\left(26-63 \mathrm{~kg} / \mathrm{m}^{3}\right)$ are equivalent to melt fractions in the range of $4.7-11.8 \%$. If we eliminate the estimates obtained for the region south of $8^{\circ} 15 ' \mathrm{~S}$ where, as discussed above, the estimates of the compensation depth are probably too low, then the upper bound on the melt fraction is reduced to $9.3 \%$. Note that this does not represent the total amount of partial melting undergone by the mantle but is the percentage of melt present at this particular time. This melt must be moving very quickly through the mantle to the surface. Assuming that all of the melt is incorporated into 6-km-thick oceanic crust with an average density of $2800 \mathrm{~kg} / \mathrm{m}^{3}$ and that it is evenly distributed along the axis, the magma implied by the melt fractions determined from the gravity anomalies with $C_{1}=70 \mathrm{~m} / \mathrm{m} . y .{ }^{1 / 2}$ will create a ribbon of crust $1.72 \mathrm{~km}$ wide along the $7^{\circ} 12^{\prime} \mathrm{S}-8^{\circ} 38^{\prime} \mathrm{S}$ ridge segment for growing plate model, and $1.71 \mathrm{~km}$ wide for the constant rigidity model. This represents only $11.9 \mathrm{kyr}$ of crustal accretion.

The form of mantle flow beneath mid-ocean ridges has been the subject of considerable discussion. There is general agree- ment that a significant portion of the magmas erupted at ridge axes form at depths of 30-50 km [Klein and Langmuir, 1987; Mackenzie and Bickle, 1988]. Most models of plate motion driven mantle flow predict that decompression melting at these depths should occur over a wide area centered at the axis [e.g., Ahern and Turcotte, 1979; Phipps Morgan, 1987; Sparks and Parmentier, 1991; Spiegelman and Mackenzie, 1987]. The problem is then to determine a mechanism which will cause magma generated over such a broad region to be erupted in a very narrow region at the axis. There are two general types of models. In one group, mechanisms such as viscous pressure gradients [Spiegelman and Mackenzie, 1987] or anisotropic permeability [Phipps Morgan, 1987; Sparks and Parmentier, 1991] are proposed to drive melt toward the ridge axis, while the mantle flow pattern is basically that of simple plate separation driven corner flow. In these models, melt is present in a broad zone below the axis. The second group of models [Buck and Su, 1989; Scott and Stevenson, 1989; Sotin and Parmentier, 1989] proposes that buoyancy effects related to melt extraction serve to focus mantle flow in a narrow upwelling zone beneath the axis. Our gravity study implies focused upwelling in a narrow zone and thus favors the second group of models.

The buoyant force, and thus the upwelling, is not evenly distributed along the axis. Tables 2 and 3 and Figure 14 show that the mass deficiency is centered in the central and to a lesser extent the southern portion of the ridge segment. The mass

TABLE 3. Model Results: Variable Rigidity (Growing) Plate

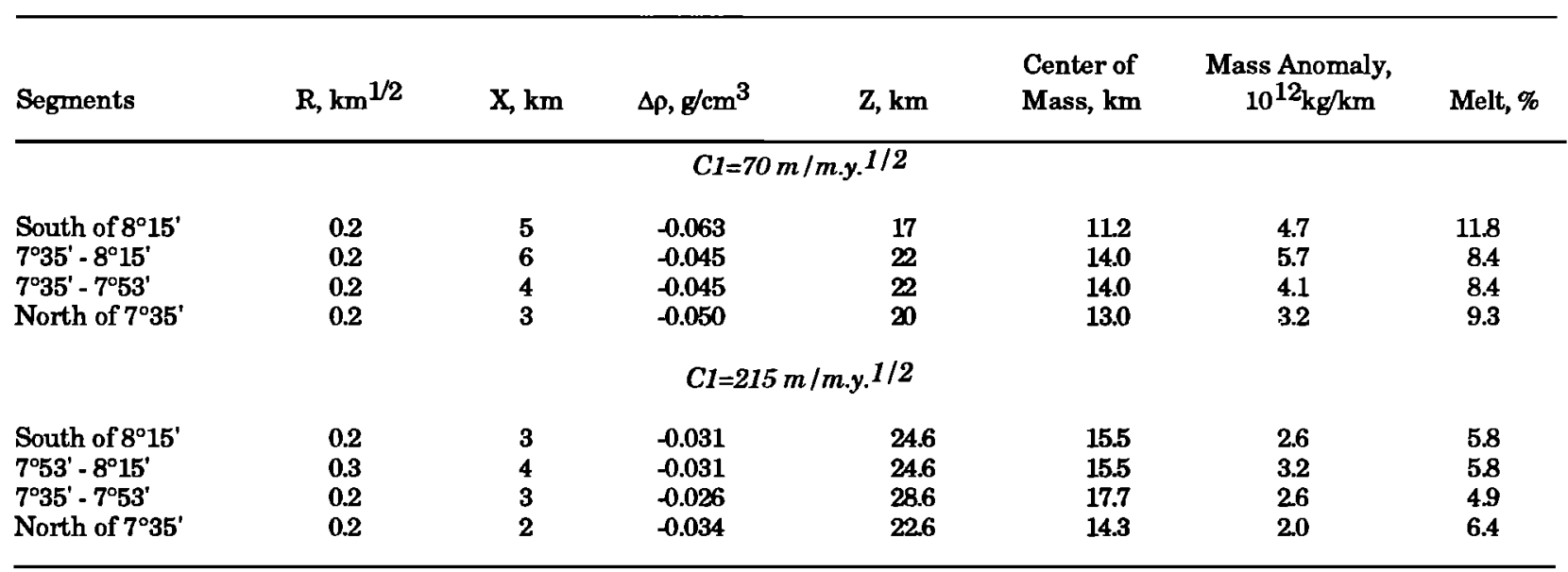




$$
\mathrm{C} 1=70 \mathrm{~m} / \mathrm{m} \cdot \mathrm{y} .^{-1 / 2}
$$
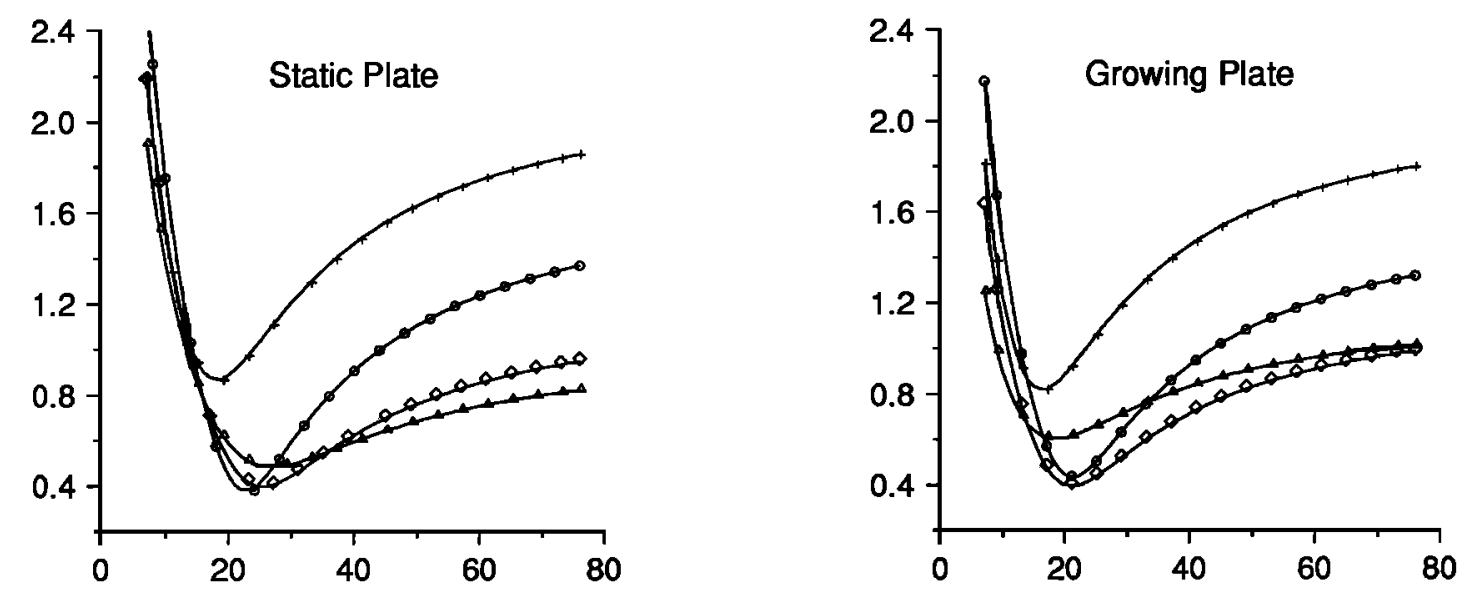

$$
\mathrm{C} 1=215 \mathrm{~m} / \mathrm{m} . \mathrm{y} \text {. }
$$
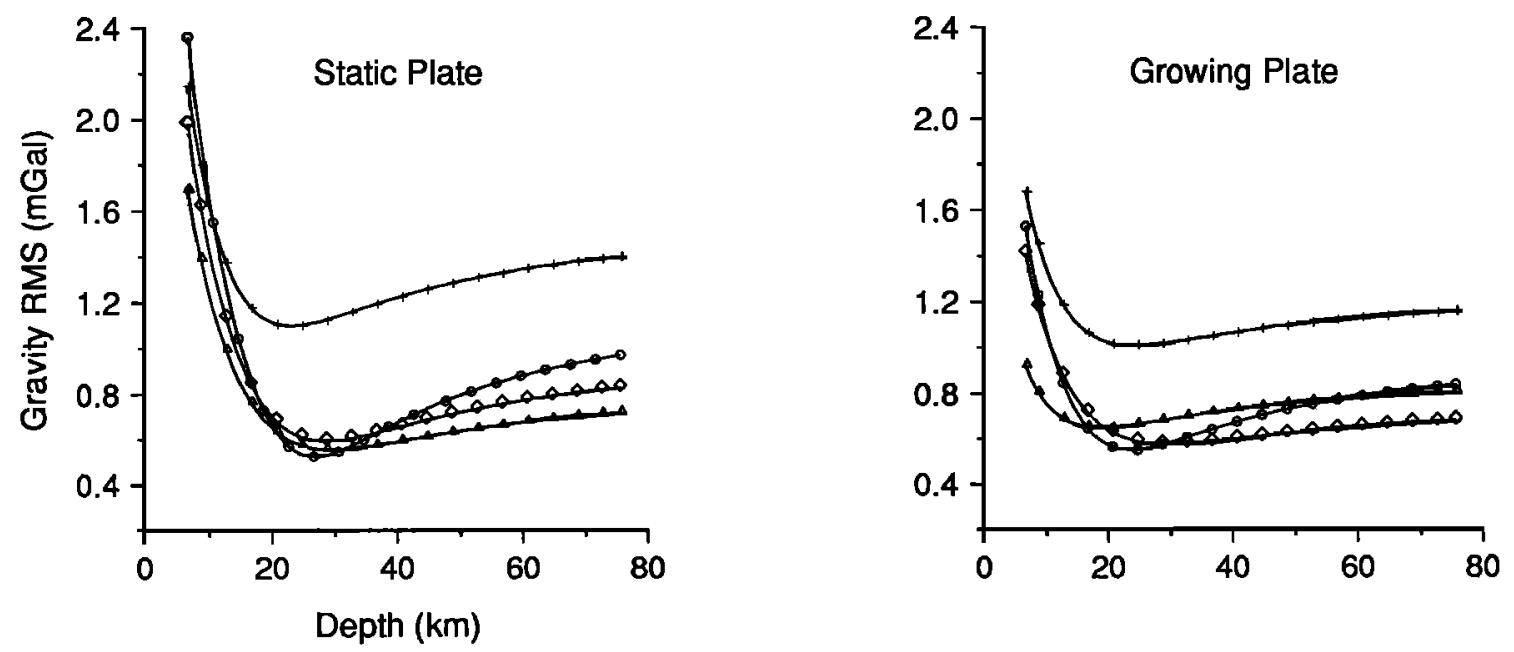

Fig. 11. The rms misfit between residual gravity anomalies and gravity anomalies calculated for elastic plate models which best fit the residual bathymetry. Gravity misfit is plotted against the depth below the sea surface to which the buoyant mass is distributed, assuming a constant density. The top of the low-density region is assumed to be at a depth of $4 \mathrm{~km}$ below the sea surface (1.3 km below the seafloor). The gravity data constrain the mass deficiency to extend to a depth of $20-30 \mathrm{~km}$ for all models. The symbols used to distinguish the different regions are cross for south of $8^{\circ} 15^{\prime} \mathrm{S}$, circle for $7^{\circ} 53^{\prime} \mathrm{S}-8^{\circ} 15^{\prime} \mathrm{S}$, square for $7^{\circ} 35^{\prime} \mathrm{S}-8^{\circ} 15^{\prime} \mathrm{S}$, and triangle for north of $7^{\circ} 35^{\prime} \mathrm{S}$.

anomaly per kilometer of ridge axis beneath the $7^{\circ} 53^{\prime} \mathrm{S}-8^{\circ} 15^{\prime} \mathrm{S}$ section of axis is 1.6-1.8 times that beneath the section to the north of $7^{\circ} 35 \mathrm{~S}$. Since the ridge axis appears magmatically active throughout the entire $7^{\circ} 12^{\prime} \mathrm{S}-8^{\circ} 38^{\prime} \mathrm{S}$ segment [Cochran et al., 1993], an efficient shallow level plumbing system must exist to redistribute the magma evenly along the ridge axis. This implies that the deep upwelling must be even more focused than is implied by the mass distribution shown in Figure 14, since much of the melt beneath the ends of the segment must have ascended under the center of the segment and have moved laterally in the shallow plumbing system.

It has been suggested by Parmentier and Phipps Morgan [1990] and by Lin and Phipps Morgan [1992] that differences in the along-axis gravity and depth patterns observed at slow spreading and at fast spreading ridges can be explained by a change from three-dimensional, "plumelike" upwelling beneath slow spreading ridges to two-dimensional, "sheetlike" upwelling beneath fast spreading ridges. Our analysis of the gravity and bathymetry variations along the fast spreading southern East Pacific Rise indicates that deep upwelling is focused or "plumelike" under the crest of this ridge segment.

It appears that the differences in axial gravity and depth pat- terns between fast and slow spreading ridges reflect differences in the efficiency of the shallow along-axis magma distribution. Although an efficient along-axis plumbing system must exist beneath the fast spreading southern EPR, it is reasonable that at slow spreading rates the lithosphere thickens and cools rapidly enough with distance from the axis that it is not possible to establish any significant along-axis flow of magma. If the melt implied by the mass deficiency beneath the EPR ridge crest were to ascend vertically and freeze in place, systematic crustal thickness variations of about a factor of 2 would result within the ridge segment. Assuming that the melt beneath the ridge crest implied by our constant thickness plate $\left(C_{1}=\right.$ $70 \mathrm{~m} / \mathrm{m} . y^{1 / 2}$ ) model represents a $11.9 \mathrm{kyr}$ supply to the surface, the crustal thickness would vary from $4.0 \mathrm{~km}$ in the north to $7.5 \mathrm{~km}$ in the center of the segment. These crustal thickness variations are similar to those suggested along the MidAtlantic Ridge on the basis of gravity variations [Lin et al., 1990; Lin and Phipps Morgan, 1992] and observed there from seismic studies [Purdy and Detrick, 1986].

Since the gravity effect of the upwelling partial melt in the mantle beneath the ridge axis is fairly modest compared to the gravity anomalies observed at slow spreading ridges, it is rea- 

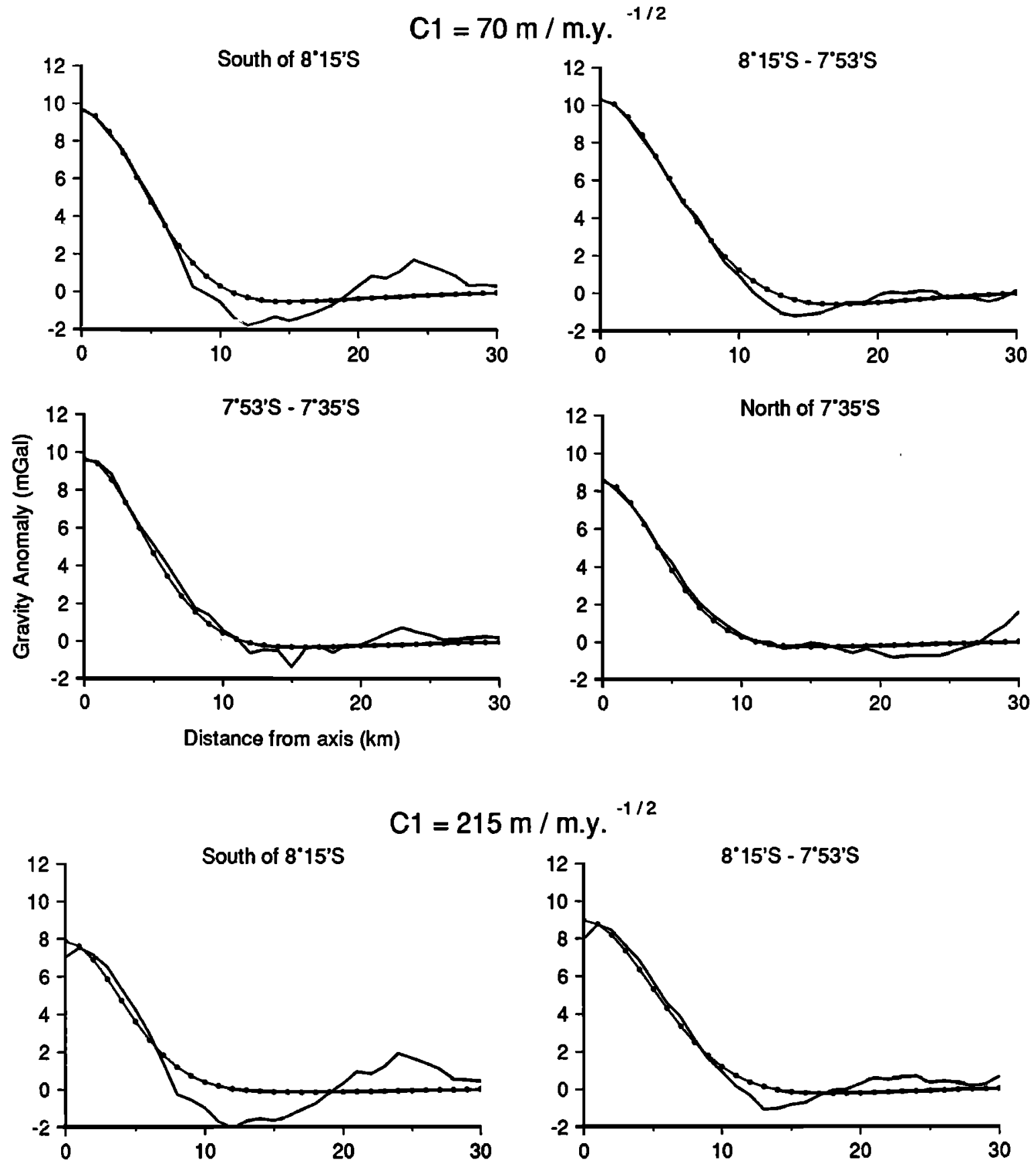

$-1 / 2$
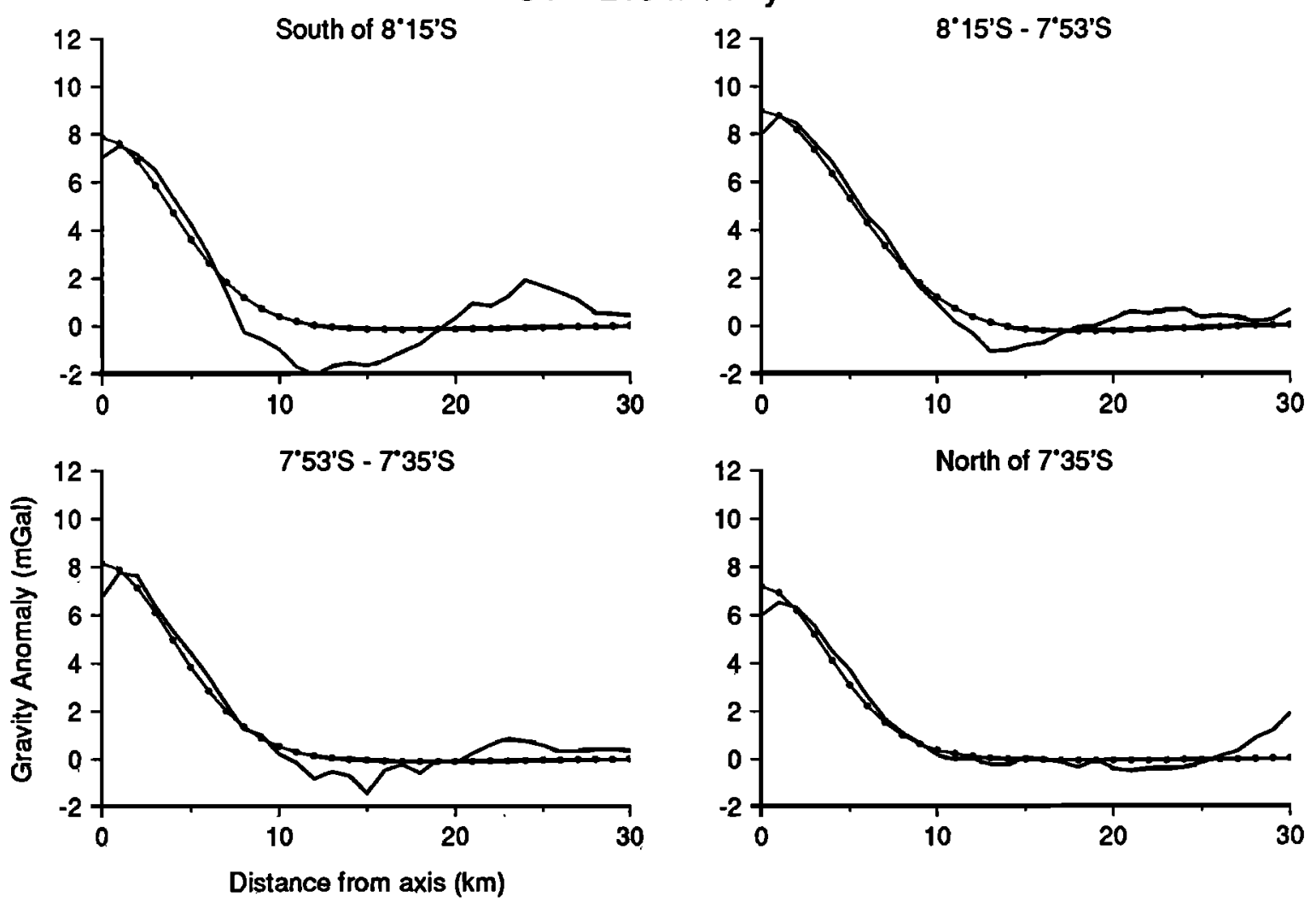

Fig. 12a. Comparison of best fitting gravity anomalies calculated for a constant rigidity (static) elastic plate model with residual gravity anomalies for four portions of the $7^{\circ} 12$ 'S- $8^{\circ} 38$ 'S ridge segment. Parameters used in the calculations are shown in Table 2. 


$$
\text { C1 }=70 \mathrm{~m} / \mathrm{m}_{\mathrm{y}} \mathrm{.}^{-1 / 2}
$$
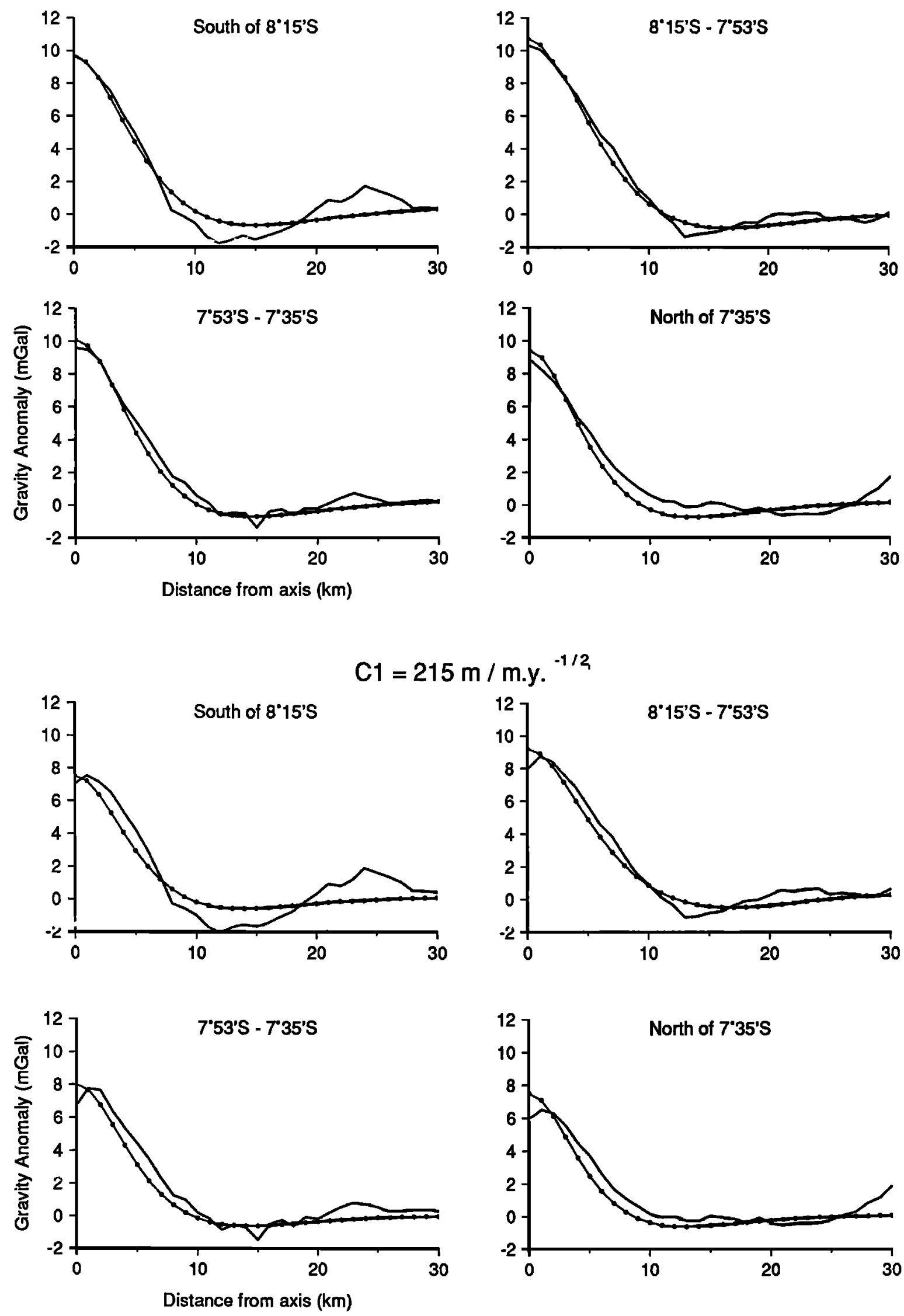

Fig. 12b. Comparison of best fitting gravity anomalies calculated for a growing elastic plate model with residual gravity anomalies for four portions of the $7^{\circ} 12^{\prime} \mathrm{S}-8^{\circ} 38^{\prime} \mathrm{S}$ ridge segment. Parameters used in the calculations are shown in Table 3. 


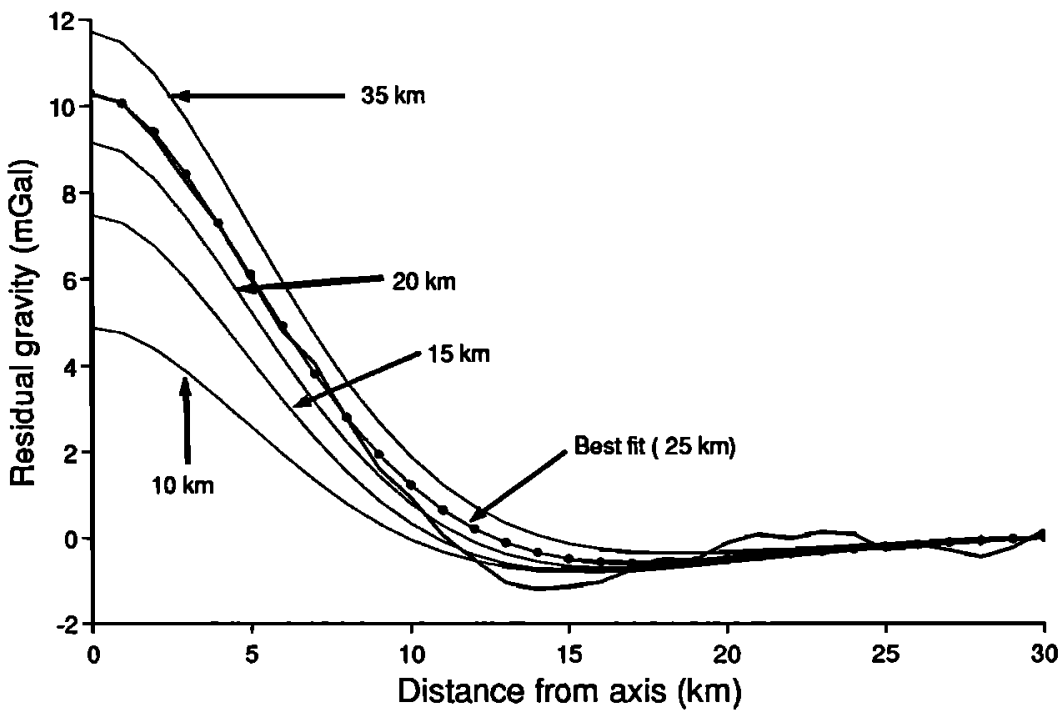

Fig. 13. Examination of the sensitivity of calculated gravity anomalies to the depth to which the low-density region extends. Heavy line shows the observed residual gravity anomaly profile for the $7^{\circ} 53^{\prime} \mathrm{S}-8^{\circ} 15^{\prime} \mathrm{S}$ region for constant rigidity plate with $C_{1}=70 \mathrm{~m} / \mathrm{m} . y^{1 / 2}$. Thin lines show gravity anomalies calculated when the anomalous mass necessary to produce the residual bathymetric profile is distributed to various depths. Note that the calculated gravity anomalies rapidly become much smaller than the observed anomaly when the base of the low-density region is brought shallower than about $20 \mathrm{~km}$.

sonable that the along-axis gravity variations noted at slow spreading ridges do result in large part from along-axis variations in crustal structure. Crustal thickness variations inferred along the axis of the Mid-Atlantic Ridge from gravity anomalies [Kuo and Forsyth, 1988; Lin et al., 1990] are very close to those needed to compensate the observed axial depth variations in a local "Airy" manner. It thus appears that there may be very little along-axis transport of melt at slow spreading ridge axes and that magma is in large part injected into the crust where it ascends.

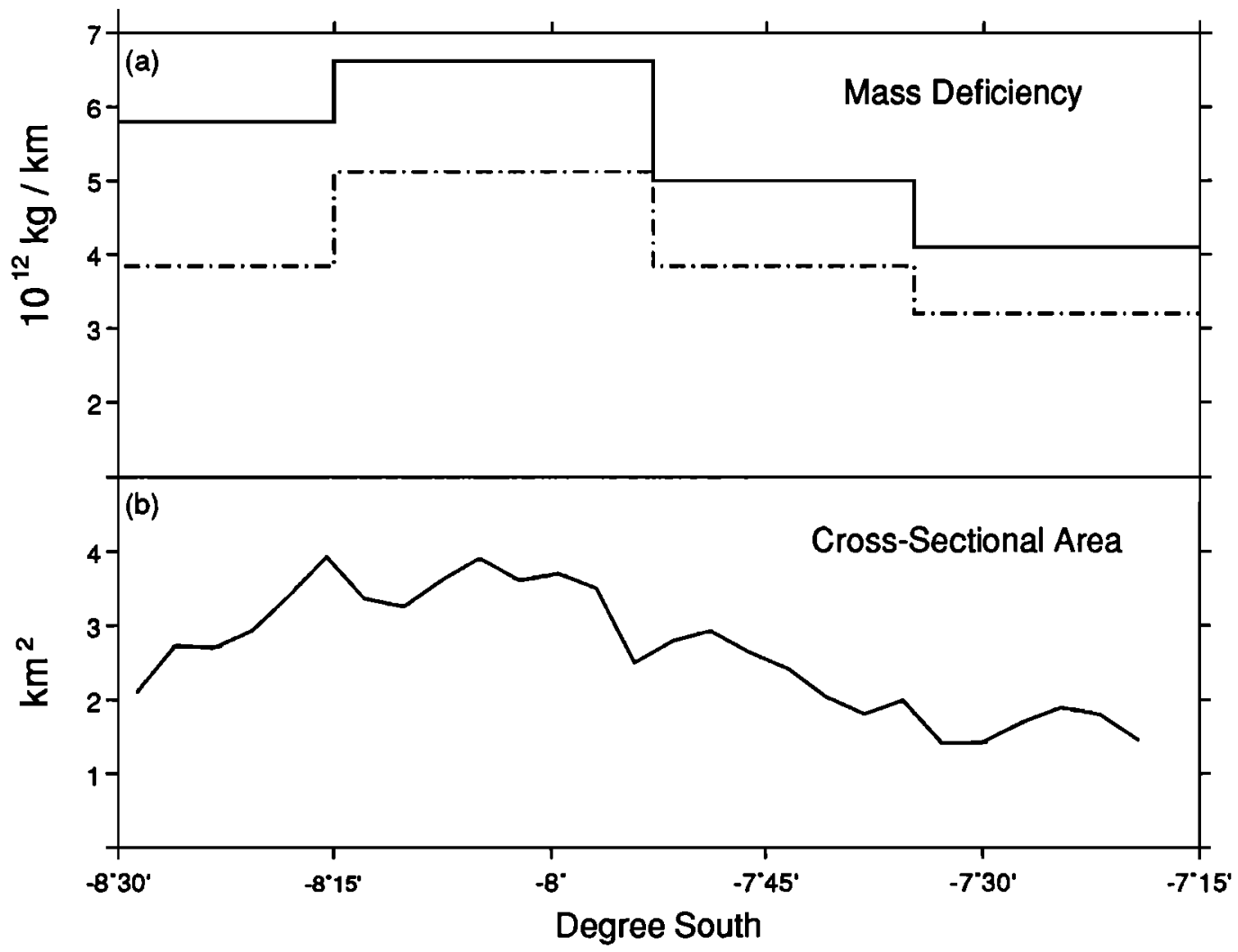

Fig. 14. (a) Distribution along the axis of the subcrestal mass deficiency determined from our flexural calculations assuming a constant rigidity plate. Solid line shows the results obtained for $C_{1}=70 \mathrm{~m} / \mathrm{m} . y .1 / 2$ and the dashed line those obtained for $C_{1}=215 \mathrm{~m} / \mathrm{m} \cdot \mathrm{y}^{1 / 2}$. (b) Along-axis profile of cross-sectional area of the crestal bathymetric high. Cross sectional area was calculated using the method of Scheirer and Macdonald [1993]. Note similarity in the shape of the mass deficiency and crosssectional area profiles. 
The morphologic indications of vigorous magmatic activity along the entire length of the $7^{\circ} 12^{\prime} \mathrm{S}-8^{\circ} 38^{\prime} \mathrm{S}$ ridge segment imply that at the superfast spreading southern EPR, there is a broad, well-connected area of elevated temperatures beneath the axis, so that a relatively efficient shallow magmatic plumbing system extends the length of the ridge segment and feeds magma into the overlying crustal magma chamber [Cochran et al., 1993]. We therefore expect that variations in crustal thickness will be smaller at a fast spreading ridge axis and that there will not necessarily be a systematic relationship between crustal thickness and position within a ridge segment. Barth [1991] did observe crustal thickness variations of $0.75 \mathrm{~s}$ (twoway travel time) or about $2.6 \mathrm{~km}$ in seismic reflection data from the northern EPR between $8^{\circ} 50^{\prime} \mathrm{N}$ and $9^{\circ} 50^{\prime} \mathrm{N}$. However, Barth [1991] found that there is no systematic relationship between crustal thickness and axial depth or mantle Bouguer anomaly. Specifically, she states "bathymetric highs and axial mantle Bouguer gravity anomaly lows are not generally assosiated with thicker seafloor-to-reflection Moho sections within our study areas" [Barth, 1991, p193].

\section{SUMMARY AND CONCLUSIONS}

The crestal region of the East Pacific Rise in the $160-\mathrm{km}$ long ridge segment between $7^{\circ} 12^{\prime} \mathrm{S}$ and $8^{\circ} 38^{\prime} \mathrm{S}$ is characterized by linear bathymetric and gravity highs. The bathymetric crestal high stands about $400 \mathrm{~m}$ above the adjacent ridge flanks and has a nearly constant minimum axial depth of about 2725 $m$ for a distance of about $140 \mathrm{~km}$ from $7^{\circ} 22$ 'S to $8^{\circ} 35^{\prime} \mathrm{S}$. The summit of the crestal high is broad and flat, and an axial summit caldera is present for the entire length of the ridge segment. Even though the summit of the crestal high has a very uniform depth and first-order appearance for nearly the entire length ridge segment, its shape varies systematically along strike [Cochran et al., 1993]. The crestal high is broad with gentle slopes $\left(<3^{\circ}\right)$ in the center of the segment but becomes progressively narrower and steeper toward the ends of the ridge segment. This change in the shape of the ridge crest is particularly marked in the northern portion of the ridge segment where the crestal high takes the form of a very steep $\left(-25^{\circ}\right)$, flat-topped ridge, $300-400 \mathrm{~m}$ high and only $2-5 \mathrm{~km}$ wide, sitting atop a low bathymetric rise (Figures 2 and 4 ).

The ridge crest is marked by a free-air gravity anomaly high about $15-20 \mathrm{~km}$ wide with an amplitude of $10-15 \mathrm{mGal}$ relative to values on the ridge flanks. The gravity high is $3-5 \mathrm{mGal}$ greater in the center of the segment than at the ends (Plate 2 top). The mantle Bouguer anomalies are characterized by a relative low over the ridge axis, reflecting the thermally compensated subsidence of the ridge flanks. Mantle Bouguer anomalies vary systematically along the axis with minimum values found near the center of the segment. The amplitude of the variation in mantle Bouguer anomaly $(10 \mathrm{mGal})$ and the gradients $(>0.1 \mathrm{mGal} / \mathrm{km}$ ) are similar to those observed at the northern EPR [Madsen et al., 1990]. The axial mantle Bouguer anomalies do not reflect the axial depth, which is constant, but are correlated with changes in the cross-sectional area of the crestal high.

We divided the $7^{\circ} 12^{\prime} \mathrm{S}-8^{\circ} 38^{\prime} \mathrm{S}$ ridge segment into four sections based on the cross-sectional shape of the crestal high and stacked bathymetry and gravity profiles across the axis from each region. The effects of cooling and subsidence away from the axis was removed from the stacked profiles to isolate residual topographic and gravity anomalies associated with the ridge crest. The residual crestal bathymetric high was modeled as a flexural feature resulting from the upward buoyant load of a region of low-density material centered beneath the axis. The lithosphere was treated as a broken plate with its free end located $0.5 \mathrm{~km}$ from the axis. The region within $0.5 \mathrm{~km}$ of the axis was considered to be locally compensated. Two litho- spheric models were considered. In one model the lithosphere is assumed to have a constant flexural rigidity, and in the second model the effective elastic thickness of the lithosphere is considered to be proportional to the square root of distance from the axis with the new material added stress-free to the base of the lithosphere [Kuo et al., 1986].

We used the bathymetry of the residual crestal high to determine the amount and horizontal extent of the subsurface mass deficiency and the residual gravity to constrain the depth to which it is distributed. The best fitting values of $T_{e}$ for the constant rigidity case are in the range of $0.3-0.6 \mathrm{~km}$. For the growing plate model, $T_{e}$ increases at a rate of $0.2-0.3 \mathrm{~km}^{1 / 2}$. The gravity constrains the mass deficiency to extend to a depth of $20-30 \mathrm{~km}$ for both lithospheric models.

The most reasonable explanation for a region of low density material centered at the ridge axis and extending to a depth of $20-30 \mathrm{~km}$ below the sea surface is that it represents a region of partial melt feeding magma to the ridge axis. The best fitting density anomalies imply that a $4.7-9 \%$ melt fraction is present beneath the crestal high.

The modeling also shows that the region of partial melt is constrained to be within a narrow region. We thus agree with Wilson [1992], who argued that compensation of the crestal high must extend to a considerable depth and that this observation favors models of magma flow in which upwelling is strongly focused near ridge axes. Our modeling constrains the region of significant partial melt to within about $8 \mathrm{~km}$ from the axis, at least to a depth of about $20 \mathrm{~km}$.

The mass deficiency, and thus the upwelling partial melt, within the $7^{\circ} 12^{\prime} \mathrm{S}-8^{\circ} 38^{\prime} \mathrm{S}$ ridge segment is not distributed evenly along the ridge axis, but rather is concentrated in the central portion of the ridge segment. The mass anomaly per kilometer of ridge axis beneath the central $\left(7^{\circ} 53^{\prime} \mathrm{S}-8^{\circ} 15^{\prime} \mathrm{S}\right)$ section of axis is 1.6-1.8 times that beneath the section to the north of $7^{\circ} 35$ 'S. The constant axial depth and evidence of vigorous magmatic activity along the entire length of the segment require the presence of an efficient shallow level plumbing system beneath the ridge axis to redistribute the magma evenly along the ridge axis. It thus appears that differences in the along-axis gravity and depth patterns observed at slow spreading and at fast spreading ridges do not result from a change from three-dimensional, focused upwelling at slow spreading ridges to two-dimensional sheetlike upwelling at fast spreading ridges. Rather, it appears that the differences in axial gravity and depth between fast and slow spreading ridges reflect differences in the efficiency of the shallow along-axis magma distribution.

Acknowledgments. We thank the officers, crew, and scientific personnel of the R/V Maurice Ewing for their assistance at sea. We are particularly grateful to Alberto Malinverno, Chris Keeley, Helen Webb, Yu Jin, Suzanne O'Hara, and Eric Halter, whose constant vigilance in the lab through long days of surveying allowed the collection of this unique data set. We thank Chris Keeley for his work in the processing of the Hydrosweep bathymetry data and for generating the bathymetric image used here as Plate 1. Discussions with Alberto Malinverno and Roger Buck have been very valuable, as have their comments and criticisms of the manuscript. We thank Don Forsyth, John Madsen, and Alistair Harding for thoughtful reviews of the manuscript. This research was supported by National Science Foundation grant OCE-89-11376. Lamont-Doherty contribution 5117.

\section{REFERENCES}

Ahern, J. L., and D. L. Turcotte, Magma migration beneath an ocean ridge, Earth Planet. Sci. Lett., 45, 115-122, 1979.

Barth, G. A., A marine seismic study of the East Pacific Rise, $8^{\circ} 50^{\prime} \mathrm{N}$ to $13^{\circ} 30$ N, Ph.D. thesis, 237 pp., Columbia Univ., New York, 1991.

Bell, R. E., and A. B. Watts, Evaluation of the BGM-3 sea gravity meter system onboard R/V Conrad, Geophysics, 51, 1480-1493, 1986. 
Blackman, D. K., and D. W. Forsyth, Isostatic compensation of tectonic features of the Mid-Atlantic Ridge: $25-27^{\circ} \mathrm{S}, \mathrm{J}$. Geophys. Res, $96,11,741-11,758,1991$.

Buck, W. R., and W. Su, Focused upwelling below mid-ocean ridges due to feedback between viscosity and melting, Geophys. Res. Lett., $16,641-644,1989$.

Burnett, M. S., D. W. Caress, and J. A. Orcutt, Tomographic image of the magma chamber at $12^{\circ} 50^{\prime} \mathrm{N}$ on the East Pacific Rise, Nature, 339, 206-208, 1989.

Chayes, D. N., Hydrosweep-DS on the R/V Ewing, in Oceans 91: Ocean Technologies and Opportunities in the Pacific for the 90's, vol. 2 pp. 737-742, Institute of Electrical and Electronics Engineers, Pascataway, N. J., 1991.

Cochran, J. R., An analysis of isostasy in the worlds oceans, 2, Midocean ridge crests, J. Geophys. Res., 84, 4713-4729, 1979.

Cochran, J. R., Variations in subsidence rates along intermediate and fast spreading mid-ocean ridges., Geophys. J. R. Astron. Soc., 87, 421-454, 1986

Cochran, J. R., J. A. Goff, A. Malinverno, D. J. Fornari, C. Keeley, and $\mathrm{X}$. Wang, Morphology of a "superfast" mid-ocean ridge crest and flanks: The East Pacific Rise, $7^{\circ}-9^{\circ} \mathrm{S}$, Mar. Geophys. Res., 15, 65-75, 1993.

CYAMEX, First manned submersible dives on the East Pacific Rise at $21^{\circ} \mathrm{N}$ (Project RITA): General results, Mar. Geophys. Res., 4, 345379, 1981.

Davis, E. E., and C. R. B. Lister, Fundamentals of ridge crest topography, Earth Planet. Sci. Lett., 21, 405-413, 1974.

Demets, C., R. G. Gordon, D. F. Argus, and S. Stein, Current plate motions, Geophys. J. Int., 101, 425-478, 1990.

Detrick, R. S., P. Buhl, E. E. Vera, J. C. Mutter, J. A. Orcutt, J. A Madsen, and T. M. Brocher, Multichannel seismic imaging of the axial magma chamber along the East Pacific Rise between $9^{\circ} \mathrm{N}$ and $13^{\circ} \mathrm{N}$, Nature, 326, 35-41, 1987.

Detrick, R. S., A. Harding, J. Orcutt, G. Kent, P. Buhl, J. Mutter, and E Vera, A two-ship multichannel seismic reflection and OBS experiment on the East Pacific Rise south of the Garrett Fracture Zone (abstract), Eos Trans. AGU, 72 (44), Fall Meeting suppl., 506, 1991.

Fornari, D. J., J. R. Cochran, A. Malinverno, Y. Jin, C. Keeley, X. Wang, $H$. Webb, and J. A. Goff, Preliminary results of a Hydrosweep survey of the "superfast" EPR from $7^{\circ} \mathrm{S}$ to $9.7^{\circ} \mathrm{S}$ : The Wilkes Transform (abstract), Eos Trans. AGU, 72 (44), Fall Meeting suppl., 525, 1991.

Goff, J. A., A. Malinverno, J. R. Cochran, and D. J. Fornari, The initiation of microplates along the East Pacific Rise: Off-axis seafloor morphology $9^{\circ}-7^{\circ} \mathrm{S}$, Eos Trans. AGU, 73 (14), Spring Meeting suppl., 314, 1992.

Goff, J. A., D. J. Fornari, J. R. Cochran, C. Keeley, and A. Malinverno, The Wilkes transform system and "nannoplate", Geology, 21, 623-626, 1993.

Grant, J. A., and R. Schreiber, Modern swathe sounding and sub-bottom profiling technology for research applications: The Atlas Hydrosweep and Parasound systems, Mar. Geod., 12, 9-19, 1990.

Gutberlet, M., and H. W. Schenke, HYDROSWEEP: New era in high precision bathymetric surveying in deep and shallow water, Mar. Geophys. Res., 13, 1-23, 1989.

Hale, L. D., C. J. Morton, and N. H. Sleep, Reinterpretation of seismic data over the East Pacific Rise, J. Geophys. Res., 87, 7707-7717, 1982.

Harding, A. J., J. A. Orcutt, M. E. Kappus, E. E. Vera, J. C. Mutter, P. Buhl, R. S. Detrick, and T. M. Brocher, Structure of young oceanic crust at $13^{\circ} \mathrm{N}$ on the East Pacific Rise from expanding spread profiles, J. Geophys. Res., 94, 12,163-12,196, 1989.

Haxby, W. F., and D. L. Turcotte, On isostatic geoid anomalies, $J$. Geophys. Res., 83, 5473-5478, 1978.

Haymon, R. M., D. J. Fornari, M. H. Edwards, S. Carbotte, D. Wright, and $\mathrm{K}$. C. Macdonald, Hydrothermal vent distribution along the East Pacific Rise crest $\left(9^{\circ} 09^{\prime}-54 \mathrm{~N}\right)$ and its relationship to magmatic and tectonic processes on fast-spreading mid-ocean ridges, Earth Planet. Sci. Lett., 104, 513-534, 1991.

Herron, T. J., W. J. Ludwig, P. L. Stoffa, T. K. Kan, and P. Buhl, Structure of the East Pacific Rise crest from multichannel seismic reflection data, J. Geophys. Res., 83, 798-804, 1978.

Herron, T. J., P. L. Stoffa, and P. Buhl, Magma Chamber and Mantle reflections-East Pacific Rise, Geophys. Res. Lett., 7, 989-992, 1980.

Klein, E. M., and C. H. Langmuir, Global correlations of ocean ridge basalt chemistry with axial depth and crustal thickness, $J$. Geophys. Res., 92, 8089-8115, 1987.

Kuo, B. Y., and D. W. Forsyth, Gravity anomalies of the ridge-transform system in the south Atlantic between 31 and $34.5^{\circ} \mathrm{S}$ : Upwelling centers and variations in crustal thickness, Mar. Geophys. Res., 10, 205-232, 1988.

Kuo, B. Y., D. W. Forsyth, and E. M. Parmentier, Flexure and thickening of the lithosphere at the East Pacific Rise, Geophys. Res. Lett., $13,681-684,1986$.

Lewis, B. T. R., Isostasy, magma chambers and plate driving forces on the East Pacific Rise, J. Geophys. Res., 86, 4868-4880, 1981.

Lewis, B. T. R., Constraints on the structure of the East Pacific Rise from gravity, J. Geophys. Res., 87, 8491-8500, 1982.

Lewis, B. T. R., The East Pacific Rise and the thermal model, $J$. Geophys. Res., 88, 3348-3354, 1983.

Lin, J., and J. Phipps Morgan, The spreading rate dependence of threedimensional mid-ocean ridge gravity structure, Geophys. Res. Lett., $19,13-16,1992$.

Lin, J., G. M. Purdy, H. Shouten, J. C. Sempere, and C. Zervas, Evidence from gravity data for focussed magmatic accretion along the Mid-Atlantic Ridge, Nature, 344, 627-632, 1990.

Lonsdale, P. F., Regional shape and tectonics of the Equatorial East Pacific Rise, Mar. Geophys. Res., 3, 295-315, 1977a.

Lonsdale, P. F., Structural geomorphology of a fast-spreading rise crest: The East Pacific Rise near $3^{\circ} 25$ 'S, Mar. Geophys. Res., 3, 251-293, 1977b.

Lonsdale, P. F., Segmentation of the Pacific-Nazca spreading center, $1^{\circ} \mathrm{N}-20^{\circ} \mathrm{S}, \mathrm{J}$. Geophys. Res., 94, 12,197-12,225, 1989.

Louden, K. E., Marine heat flow data listing, in Handbook of Seafloor Heat Flow, edited by J. A. Wright and K. E. Louden, pp. 325-485, CRC Press, Boca Raton, Fla., 1989.

Macdonald, K. C., Mid-ocean ridges: Fine scale tectonic volcanic and hydrothermal processes within the plate boundary zone, Annu. Rev. Earth Planet. Sci., 10, 155-190, 1982.

Macdonald, K. C., and P. J. Fox, The axial summit graben and crosssectional shape of the East Pacific Rise as indicators of axial magma chambers and recent volcanic eruptions, Earth Planet. Sci. Lett., 88, 119-131, 1988.

Macdonald, K. C., and B. P. Luyendyk, Investigation of faulting and abyssal hill formation on the flanks of the East Pacific Rise $\left(21^{\circ} \mathrm{N}\right)$ using Alvin, Mar. Geophys. Res., 7, 515-535, 1985.

Macdonald, K. C., P. J. Fox, L. J. Perram, M. F. Eisen, R. M. Haymon, S. P. Miller, S. M. Carbotte, M. H. Cormier, and A. N. Shor, A new view of the mid-ocean ridge from the behaviour of ridge-axis discontinuities, Nature, 335, 217-225, 1988.

Macdonald, K. C., R. Haymon, and A. Shor, A $220 \mathrm{~km}^{2}$ recently erupted lava field on the the East Pacific Rise near lat $8^{\circ} \mathrm{S}$, Geology, 17, 212-216, 1989.

Mackenzie, D., and M. J. Bickle, The volume and composition of melt generated by extension of the lithosphere, J. Petrol., 29, 625-679, 1988.

Madsen, J. A., D. W. Forsyth, and R. S. Detrick, A new isostatic model for the East Pacific Rise crest, J. Geophys. Res., 89, 9997-10,016, 1984.

Madsen, J. A., R. S. Detrick, J. C. Mutter, P. Buhl, and J. C. Orcutt, A two- and three-dimensional analysis of gravity anomalies associated with the East Pacific Rise at $9^{\circ} \mathrm{N}$ and $13^{\circ} \mathrm{N}, J$. Geophys. Res., 95, 4967-4987, 1990.

McClain, J. S., J. A. Orcutt, and M. Burnett, The East Pacific Rise in cross section: A seismic model, J. Geophys. Res., 90, 8627-8639, 1985.

McNutt, M., Compensation of oceanic topography: An application of the response function technique to the Surveyor area, J. Geophys. Res., 84, 7589-7598, 1979.

Menard, H. W., Sea floor spreading, topography and the second layer, Science, 157, 923-924, 1967.

Moritz, H., Geodetic Reference System 1980, Bull. Geod., 58, 388$398,1984$.

Ockendon, J. R., and D. L. Turcotte, On the gravitational and field anomalies due to thin mass layers, Geophys. J. R. Astron. Soc, 48, 479-492, 1977.

Parker, R. L., The rapid calculation of potential anomalies, Geophys. J. R. Astron. Soc., 31, 447-455, 1973.

Parker, R. L., and D. W. Oldenburg, Thermal model of ocean ridges, Nature Phys. Sci., 242, 137-139, 1973.

Parmentier, E. M., and J. Phipps Morgan, Spreading rate dependence of three-dimensional structure in oceanic spreading centres, Nature, 
348, 325-328, 1990.

Parsons, B., and J. G. Sclater, Ocean floor bathymetry and heat flow, $J$. Geophys. Res., 82, 803-827, 1977.

Phipps Morgan, J., Melt migration beneath mid-ocean ridge spreading centers, Geophys. Res. Lett., 14, 1238-1241, 1987.

Phipps Morgan, J., Mid-ocean ridge dynamics: Observation and theory, Rev. Geophys., 29, 807-822, 1991.

Prince, R. A., and D. W. Forsyth, A simple objective method for minimizing crossover errors in marine gravity data, Geophysics, 49. 1070-1083, 1984.

Prince, R. A., and D. W. Forsyth, Horizontal extent of anomalously thin crust near the Vema Fracture Zone from the three-dimensional analysis of gravity anomalies, J. Geophys. Res., 93, 8051-8063, 1988.

Purdy, G. M., and R. S. Detrick, Crustal structure of the Mid-Atlantic Ridge at $23^{\circ} \mathrm{N}$ from seismic refraction, J. Geophys. Res., 91, 3739$3762,1986$.

Scheirer, D. S., and K. C. Macdonald, Variation in cross-sectional area of the axial ridge along the East Pacific Rise: Evidence for the magmatic budget of a fast-spreading center, J. Geophys. Res., 98, 7871-7885, 1993.

Scott, D. R., and D. J. Stevenson, A self-consistent model of melting, magma migration and buoyancy-driven circulation beneath midocean ridges, J. Geophys. Res., 94, 2973-2988, 1989.

Searle, R. C., GLORIA survey of the East Pacific Rise near $3.5^{\circ} \mathrm{S}$ : Tectonic and volcanic characteristics of a fast spreading mid-ocean rise, Tectonophysics, 101, 319-344, 1984.

Sinton, J. M., and R. S. Detrick, Mid-ocean ridge magma chambers, $J$. Geophys. Res., 97, 197-216, 1992.

Smith, W. H. F., and P. Wessel, Gridding with continuous curvature splines in tension, Geophysics, 55, 293-305, 1990.

Sotin, C., and E. M. Parmentier, Dynamical consequences of compositional and thermal density stratification beneath spreading centers, Geophys. Res. Lett., 16, 835-838, 1989.

Sparks, D. W., and E. W. Parmentier, Melt extraction from the mantle beneath spreading centers, Earth. Planet. Sci. Lett., 105, 368-377, 1991.

Spiegelman, M., and D. Mackenzie, Simple 2-D models for melt extraction at mid-ocean ridges and island arcs, Earth Planet. Sci. Lett., 83, $137-152,1987$.

Stein, C. A., and S. Stein, A model for the global variation in oceanic depth and heat flow with lithospheric age, Nature, 359, 123-129, 1992.

Talwani, M., J. L. Worzel, and M. Landisman, Rapid gravity computations for two-dimensional bodies with application to the Mendicino submarine fracture zone, J. Geophys Res., 64, 49-59, 1959.

Talwani, M., B. C. Heezen, and J. L. Worzel, Gravity anomalies, physiography and crustal structure of the Mid-Atlantic Ridge. Publ. 22, Bur. Cent. Seismol. Int. Ser. A. Trav. Sci. Fac., pp. 81-111, International Union of Geology and Geophysics, Paris, 1961.

Toomey, D. R., G. M. Purdy, S. C. Solomon, and W. Wilcox, The three dimensional seismic velocity structure of the East Pacific Rise near latitude 9०30'N, Nature, 347, 639-644, 1990

Vera, E. E., J. C. Mutter, P. Buhl, J. A. Orcutt, A. J. Harding, M. E. Kappus, R. S. Detrick, and T. M. Brocher, The structure of 0- to 0.2m.y.-old oceanic crust at $9^{\circ} \mathrm{N}$ on the East Pacific Rise from expanded spread profiles, J. Geophys. Res., 95, 15,529-15,556, 1990.

Wilson, D. S., Focused upwelling beneath mid-ocean ridges: Evidence from seamount formation and isostatic compensation of topography, Earth. Planet. Sci. Lett., 113, 41-55, 1992.

J. R. Cochran and X. Wang, Lamont-Doherty Earth Observatory, Palisades, NY 10964

(Received October 19, 1992; revised April 1, 1993 accepted June 8, 1993) 